\title{
Ripple Effect of a Pandemic: Analysis of the Psychological Stress Landscape during COVID19
}

\author{
Ajay Agarwal ${ }^{1}$ \\ ${ }^{1}$ Department of Computer Science and Engineering \\ DIT University \\ Dehradun 248009 \\ India \\ \{Email: verslinfiniaudela@gmail.com\}
}

\begin{abstract}
The recent outbreak of an infectious novel coronavirus disease 2019 (nCoV-19) is significantly influencing the life style of everyone all over the world. A pandemic that has not only claimed countless lives of people across the globe, but also has struck the plain and tranquil psychological landscape of the world citizens. COVID-19's hit on the landscape has resulted in a ripple effect witnessed across the minds of people across the globe. In this paper, we aim to study this ripple effect in terms of the variations caused in psychological stress of individuals. Stress is the basic gateway to most of the other psychological disorders, as a result a comprehensive psycholingual and psychoacoustic study is conducted. This analysis is conducted for students and migrant workers for their distinctive online and offline behavioural activity. Finally, neurobiological insights regarding the implication and necessity of such studies are provided in the field of psychology and neuroscience.
\end{abstract}

\section{Introduction}

\subsection{Stress as a Comorbidity of Crisis}

Since the last decade, the world has witnessed a variety of crisis events at very short interval of times. These events have been of different nature- terrorism, natural calamity, epidemics etc. The occurrence of such events, apart from causing unfortunate loss to life and property, also entails with them a ripple effect that is witnessed across the mental health landscape of the victims and the survivors of such events [65-70]. While a significant cause to the deterioration of the psychological health of the individuals stems from the first-hand impact of the crisis event, it is a result of the preventive measures that are taken as a result of the crisis. These preventive measures, like social isolation, shutdown of essential and non-essential services, temporary lockdowns and imposed quarantines, etc. lead to an involuntary ripple effect that can provide for psychological triggers for severe mental health diseases - stress, PTSD, depression, anxiety, OCD, or even suicidal behaviour [69-70]. In our study, we discuss psychological stress as a comorbidity post public crisis events.

Stress is a major research focus in basic and clinical neuroscience research. It is often understood to be "response to stressful stimuli". This response being multifaceted in 
manifested in biological nature and in the psychological nature of the person. Subtle changes in the linguistics patterns of stressed individuals can also be seen as a response to stressful stimulus [13].

The stressful stimulus, also known as stressor, is categorized into two categories - physical and psychological. Public crisis events like terrorist attacks, or pandemic outbreak can immense capability to act as both stressors to elicit a stressful response of an individual [6970]. For example, in case of a disease outbreak, the increased susceptibility to the pathogen and the fear of catching the same, acts as a physical stressor, whereas the possible impact of the pandemic outbreak on one's work and career can acts as a psychological stressor [57-70]. Irrespective of the stressor processing, the stress system of the individual activates in a coordinated fashion having a strong positive correlation with other brain disorders such as depression, anxiety and PTSD, whereas, the stress is considered as the psychological phenomenon to study.

\subsection{The Neuroscience of Social Media}

Social media is a global phenomenon; it attracts a wide reaching audience of the world, and is expected to grow with time [1-4]. As a result, it acts as an important environment that researchers can make use of in order to study social behaviour and gain insights for understanding human behaviour. It provides humans the platform to fulfil basic social needs, one displays multifaceted behaviour which largely falls into three domains of cognitive processes - social cognition, self-referential cognition, and social reward processing. A great deal of offline studies has been conducted in identifying the neural systems that support these cognitive processes [71-97]. It is important to identify and analyse which online behaviour elicit the above mentioned cognitive processes [1-4].

\subsubsection{Social Cognition}

1. Before posting content, an individual is likely to think on how the individual's audience willreact to the post.

2. Before providing feedback on someone else's post, an individual is likely to think how that someone will would react on receiving the feedback.

3. On viewing a third-person's post, an individual is likely to think about the motivation of that user for putting up such a post.

\subsubsection{Self-Referential Cognition}

1. Posting content describing an individual's own subjective experience, opinions or recent past.

2. Receiving feedback on the content posted by the individual describing the above categories. This can further induce reflected self-appraisal, which in turns leads to further self-referential thoughts.

3. Social comparison with other users on the same social network can also lead to more self-referential thoughts regarding an individual's capabilities.

\subsubsection{Social Reward Processing}


1. Most of the interfaces of social media platforms provide users with consistent supply of rewards. These rewards usually are grouped into two categories - Social connection suggestion and Modes of Reputation Enhancement. While the modes of social connection suggestion involve personalised suggestions to follow certain pages or users, the later involves simples cues of "likes", "views", "hits", "retweets" etc. These cues often associate with the individual's personal success on such social media platforms.

2. As the most minimal cues of social success can prompt a human's reward behaviour, social media cues of such nature leads to a certain desire to keep revisiting the platform again and again.

Based on the research done in neuroimaging and neuroscience [14-20] [34-57], it was observed that by identifying the neuroscience of social media platforms to be strongly associated with three major cognitive processes -social cognition, self-referential cognition, and social reward processing [1].

\section{Methodology}

In this paper, we study online and offline behaviour of stressed and non-stressed individuals belonging to two specific target groups - students and migrant workers.

For online behaviour study, we consider the online behaviour of students during pandemic. Students are more likely to have a richer and dense social media volume worth extraction and analysis. The study of students can also provide us insights on how environmental stressors affect the adolescent psychology and how it contributes towards the development of an individual from early-age. It can also provide cues on how pandemics contribute towards the broadening in the mental health profiles of adolescents and how it in turn is reflected in their online behaviour. Does the open space and lack of restrictions on the choice of diction on online platforms helps in more vivid expression of feeling and desires of adolescents and whether such feelings are further intensified in terms of public crisis or stressful scenarios. [21] [2326].

Methodology for Students -We analyse the social media activity of students in terms of their content, engagement and their sentiments. This analysis is done against the control group of relaxed individuals. We use Twitter as the social media platforms for extraction and scrapping of data. The data is processed and cleaned using $\mathrm{R}$ packages. For the collection of tweets and processing of the same, the given packages of $\mathrm{R}$ shall be used -rtweet, dplyr tidyr,and Tidytext. Tidytext shall also be used for our sentiment analysis study. The task of creating Wordcloud shall be achieved using the given RStudio packages - wordcloud, wordcloud2, RColorBrewer, and tm.

The first step of this study is to identify the possible ripple effect of the COVID19 pandemic which would be analysed using wordcloud generation of tweets mentioning keywords of stress and relaxation. Wordclouds are concise data visualization tools to find the frequency distribution of words across a large corpus color-coded specific to frequency, we shall aim to find out mentions of the COVID19 pandemic, or any other non-pharmaceutical intervention 
implemented as its result (like lockdown, quarantine etc.), in the corpus of tweets mentioned by online Twitter communities, which are vocal on their own problems of psychological stress and its variations. The presence of such mentions shall justify the presence of ripple effect of COVID19 on the psychological stressed communities. Then, using the representative profiled query keywords, the tweets shall be collected via Twitter API to find the general sentiment of the most frequent words mentioned in these tweets. The words most frequent in the negative sentiment describing about the COVID19 pandemic, would be selected for further study. The selected words shall be combined with the query keywords to collect tweets mentioning the given negative sentiment keywords. This time, instead, of Twitter API, OSINT tool named Twint shall be used in order to collect corresponding metadata of such tweets. The variables of the metadata itself would be used for finding signs and symbols of psychological stress based on the diagnostic conditions established by previous literature in the field of using metadata for observing signs of psychological stress. These signs may include the time difference between a potentially stressed university student tweet and the one by a relaxed student, and a relaxed individual selected randomly. This shall make sure how the levels of psychological stress clock up against the students (same group) and individuals (universal group) who aren't stressed than the students who possibly are. Query keywords, currently stand sufficient in defining the difference between stressed student and non-stressed students, given the nature of research and the dynamics of the social media platform, Twitter.

Methodology for Migrant Workers - For our offline behaviour study, we consider the offline behaviour of migrant workers in India. As it is highly likely that the migrant workers have almost insignificant online activity, it becomes beneficial as we are able to analyse pure offline behaviour of individuals without the possibility of any discrete distribution of content on online platforms which could have result in the insufficiency of our study.

We analyse the acoustic patterns of the migrant workers describing their plight and their current situation during pandemic during interviews given to the news reporters [100]. For analysis of acoustic patterns, we make use of the open-source software PRAAT[31], primarily designed to carry out speech analysis on phonetic speech. For our interview data, we refer to migrant workers residing in the countries of India, Australia, Malaysia, and Singapore.TV interviews conducted by various new channels like NDTV, CNN Insider, BBC etc. were taken in consideration for obtaining our data [100]. For analysis, we also use the control group of 11 native speakers of the respective language of migrant workers belonging to that country, chosen at random to produce the same speech as that of the migrant workers to compare contrast.

\section{Factoring in Representativeness of Samples}

Our methodology involves in studying the psychological behaviour of students via their online activities and migrant workers via their acoustic variations. However, to reach out to any definite conclusion regarding the authenticity of our experiments, it is important to ensure that the individuals that are selected for observation and study represent the diversity and pattern of the entire target groups.

In order to factor in representativeness, the study of social media feed by students for possible signs of psychological stress, the query words in our research were designed to incorporate students studying at different levels of education system hierarchy. Hence, we shall use the query keywords - "university student", "college student" and "school student" to possibly accumulate social media feed from students at every tier of educational system. 
In the case of the migrant workers' acoustic study, the interview conducted with migrant workers residing across the globe, specifically in Singapore, Malaysia, Australia and India was collected for analysis. To ensure representativeness from a given country, several interview samples were taken which included conversation with migrant workers travelling from one city to another in the chosen country. This process ensured that the voice samples of migrant workers from different parts of a given country could be taken in our research to produce unbiased results.

The entire methodology for our research study on students and migrant workers is concisely depicted in Figure 1.

\begin{tabular}{|l|l|}
\hline $\begin{array}{l}\text { Identification of Ripple Effect by } \\
\text { COVID19 in form of } \\
\text { Psychological Stress }\end{array}$ & $\begin{array}{l}\text { Methodology for Migrant } \\
\text { Workers }\end{array}$ \\
$\begin{array}{l}\text { Tweets collection using } \\
\text { representative query } \\
\text { keywords for students }\end{array}$ & $\begin{array}{l}\text { Interview samples collection } \\
\text { of migrant workers belonging } \\
\text { to Australia, India, Malaysia } \\
\text { and Singapore }\end{array}$ \\
$\begin{array}{l}\text { Sentiment Analysis for } \\
\text { Identification of COVID19 } \\
\text { related negative terms }\end{array}$ & $\begin{array}{l}\text { Cleaning of Interview } \\
\text { samples to remove } \\
\text { interviewer's audio }\end{array}$ \\
$\begin{array}{l}\text { Metadata collection of } \\
\text { tweets using COVID19 related } \\
\text { negative terms }\end{array}$ & $\begin{array}{l}\text { Normalization of Audio } \\
\text { using open-source tools } \\
\text { like Audacity }\end{array}$ \\
$\begin{array}{l}\text { Analysis of metadata for } \\
\text { psychological stress } \\
\text { detectors }\end{array}$ \\
\hline
\end{tabular}

Figure 1. Overview of methodology chosen for each of the target group students and migrant workers.

\subsection{Observation of Students' Social Media Feed}

We analyse and observe the social media feeds of students. We analyse the ripple effect of the pandemic on the stressed community on the online platform - Twitter.

\subsubsection{Identification of Ripple Effect of the Pandemic on Stressed Communities}

We scraped 89,987 tweets with hashtag - \#stress during $1^{\text {st }}$ January 2020 to May 1, 2020 using the OSINT Framework - Twint [98]. The particular OSINT Tool allows to collect all the tweets using the query keyword along with their metadata which includes, date of post, time of post, media links, hashtag used, retweet count, likes count, comments count and other crucial details. We plot the wordcloud to understand the most frequent words in the students' tweets. The figure 2 depicts a wordcloud generated from the tweets that use the \#stress. It can be observed from the figure that the word "covid19" has occurred most frequently, this represents that corpus of tweets using the \#stress are actively involved in using the term of the pandemic in their description, showing a possible change to pandemic as a major cause of stress among world citizens. 


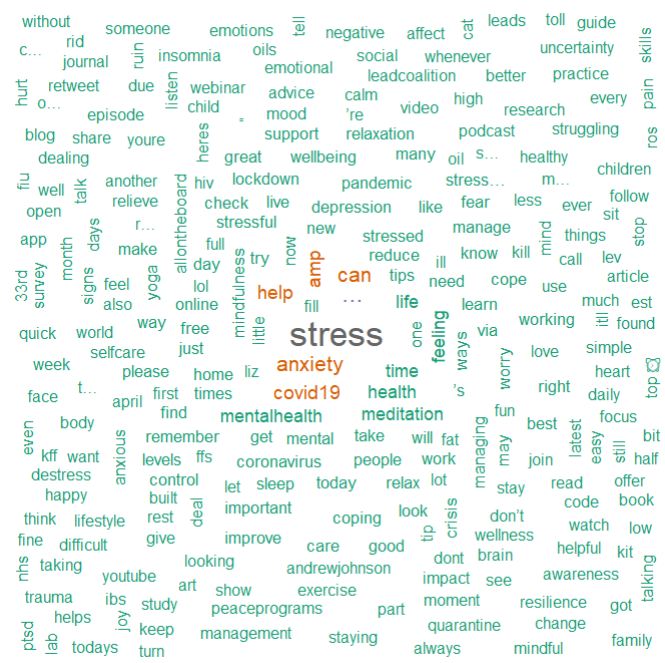

Figure 2. Wordcloud generated from the tweets corpus using the \#stress

This concludes the presence of ripple effect of the pandemic on the stressed individuals of the mental health community. It also suggests that due to the pandemic and the imposition of the non-pharmaceutical interventions, the individuals facing psychological stress are under an additional stressor i.e. pandemic. It also suggests that COVID-19 pandemic successfully qualifies to be a psychological stressor for the people.

We also generate the wordcloud of the control group of relaxed individuals with 78,342 tweets having hashtag \#relax during January 1, 2020 to May 1, 2020. However, it doesn't gain much engagement and usage of Twitter, as a result for obtaining ground truth labels of non-stressed individuals; we used the keywords - "Ifeel relaxed" and "I am feeling relaxed" [6]. The Figure 3 and figure 4 depicts the wordclouds generated with the tweets obtained with keywords "I feel relaxed" and "I am feeling relaxed" respectively, it can be observed from these figures that the word related to the pandemic is not occurring and mostly the words appearing in these tweets represent the positive sentiments.

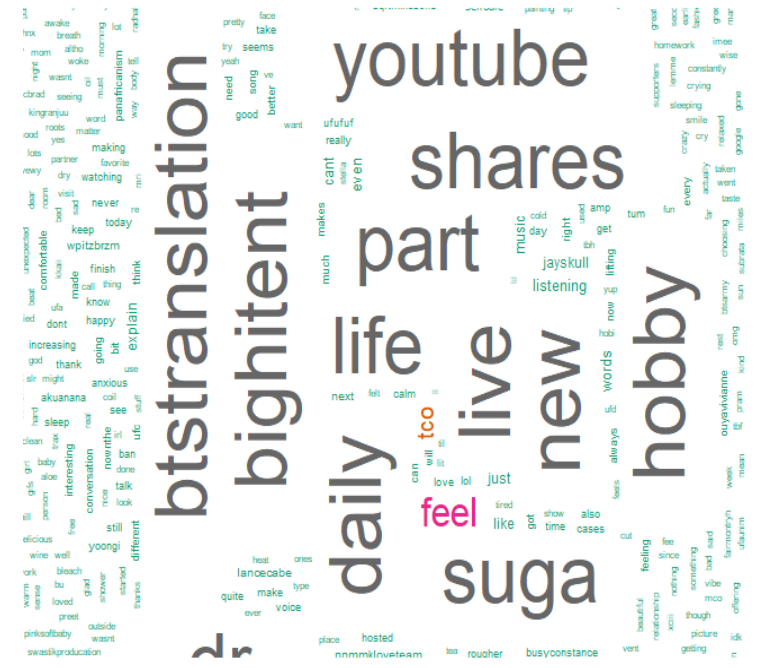

Figure 3. Wordcloud of the tweets using the keyword "Ifeel relaxed".

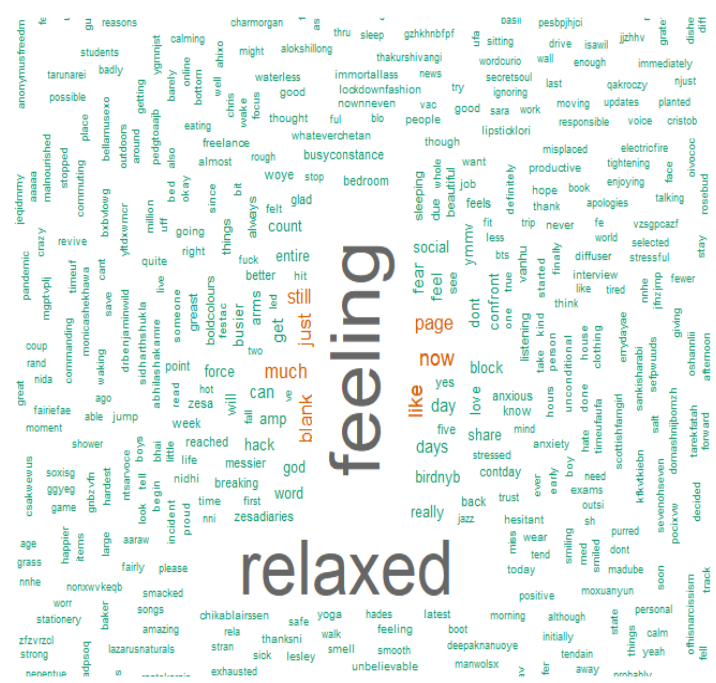

Figure 4. Wordcloud of the tweets using the keyword "I am feeling relaxed". 


\subsubsection{Sentiment Analysis of Student' Tweet Corpus}

We also scrap the tweets posted by students in different levels of the education system hierarchy. We scraped 65,343 tweets data using query the keywords- "student", "college student" and "university student", during January 1, 2020 to May 1, 2020. The aim behind this particular approach is to identify the most frequent words with positive and negative sentiments in the diction of the students tweeting during the 2019-nCoV pandemic. With the identification of most frequent negative sentiment words, we analyse possible psycholingual cues of social media that depicts the possibility of being a stress-induced tweets. We also analyse patterns in the most frequent negative sentiment words. We use Bing and AFINN Lexicon which is a part of the Tidytext package available [99] for sentiment analysis on $\mathrm{R}$ analytical software.

The Figures 5, 6, and 7 shows the most frequent words having positive and negative sentiment of the diction of tweets that include keywords of "student", "college student", and "university student" respectively. It can be observed from these figures that the common words in all the three diction of student that contribute towards the negative sentiment related to the pandemic are - "virus", and "crisis", to understand if the words "virus" and "crisis" fulfil any psycholingual detectors of stress on online platforms. This is done to identify whether such tweets are posted by students under stress or just depict negative sentiment due to the influence of environmental factors on the diction of individuals.

\section{Tweets with "student" mention}

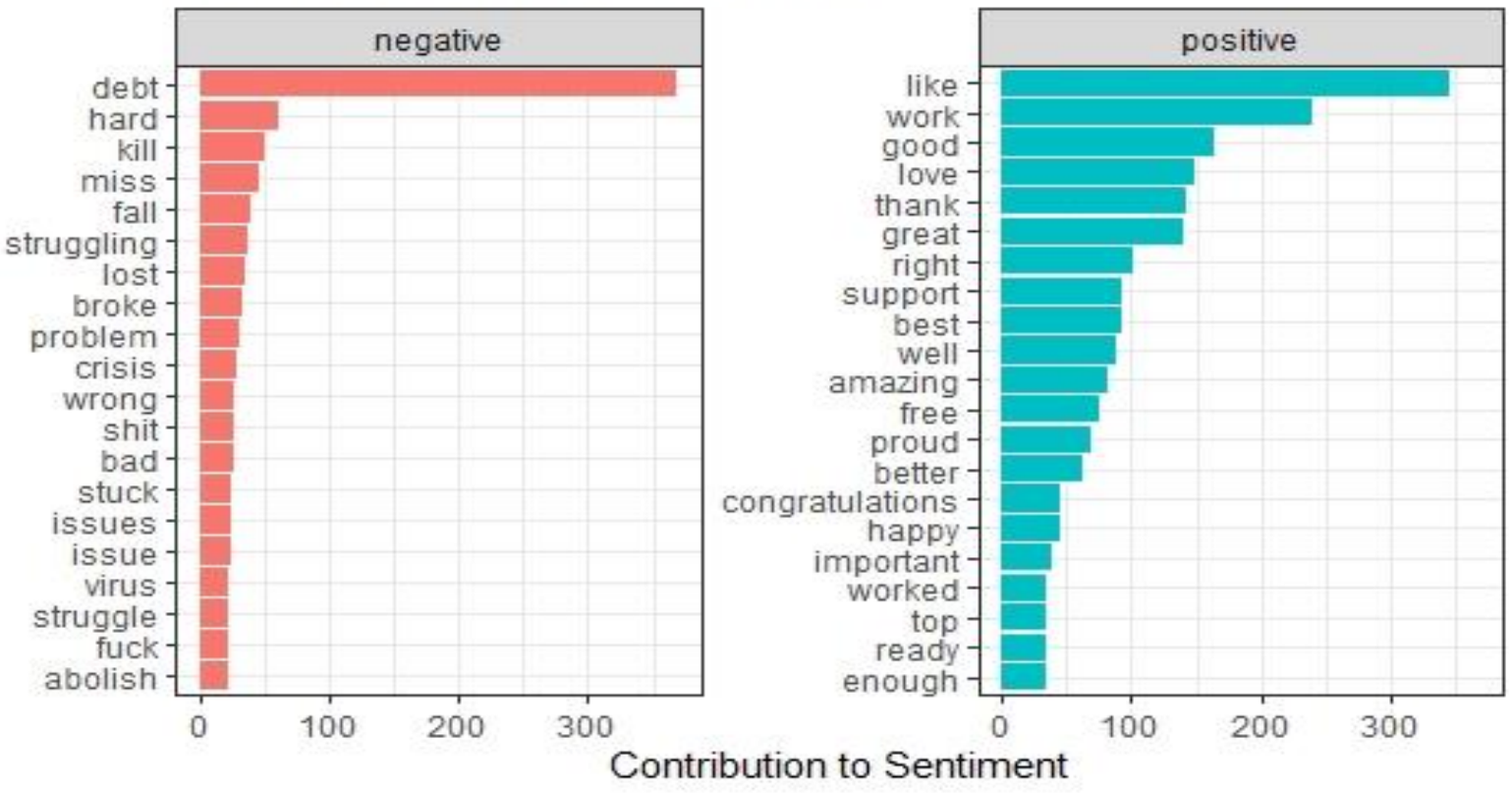

Figure 5. The most frequent words having positive and negative sentiment of the diction of tweets that include keywords of "student". 


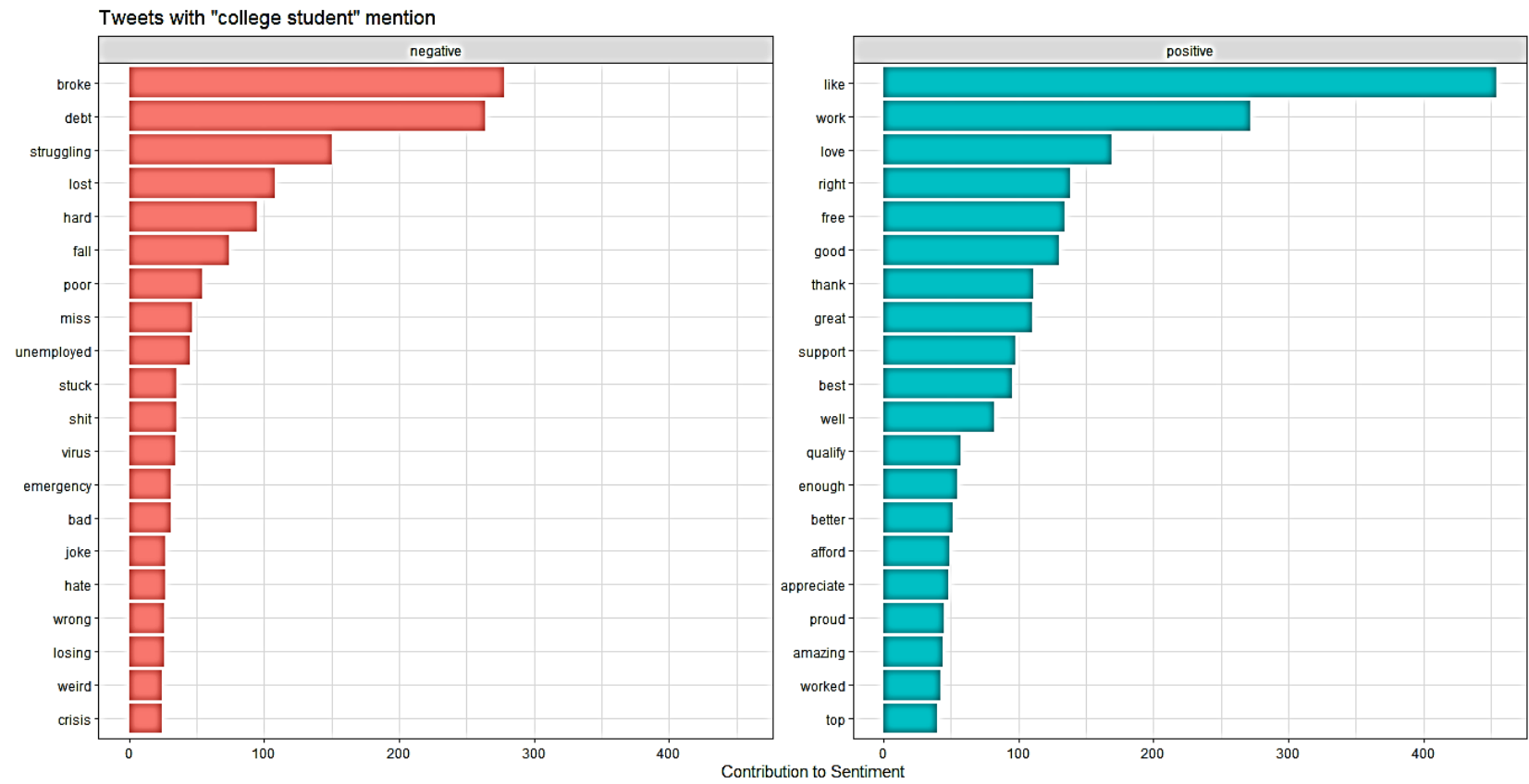

Figure 6. The most frequent words having positive and negative sentiment of the diction of tweets that include keywords of "collegestudent".

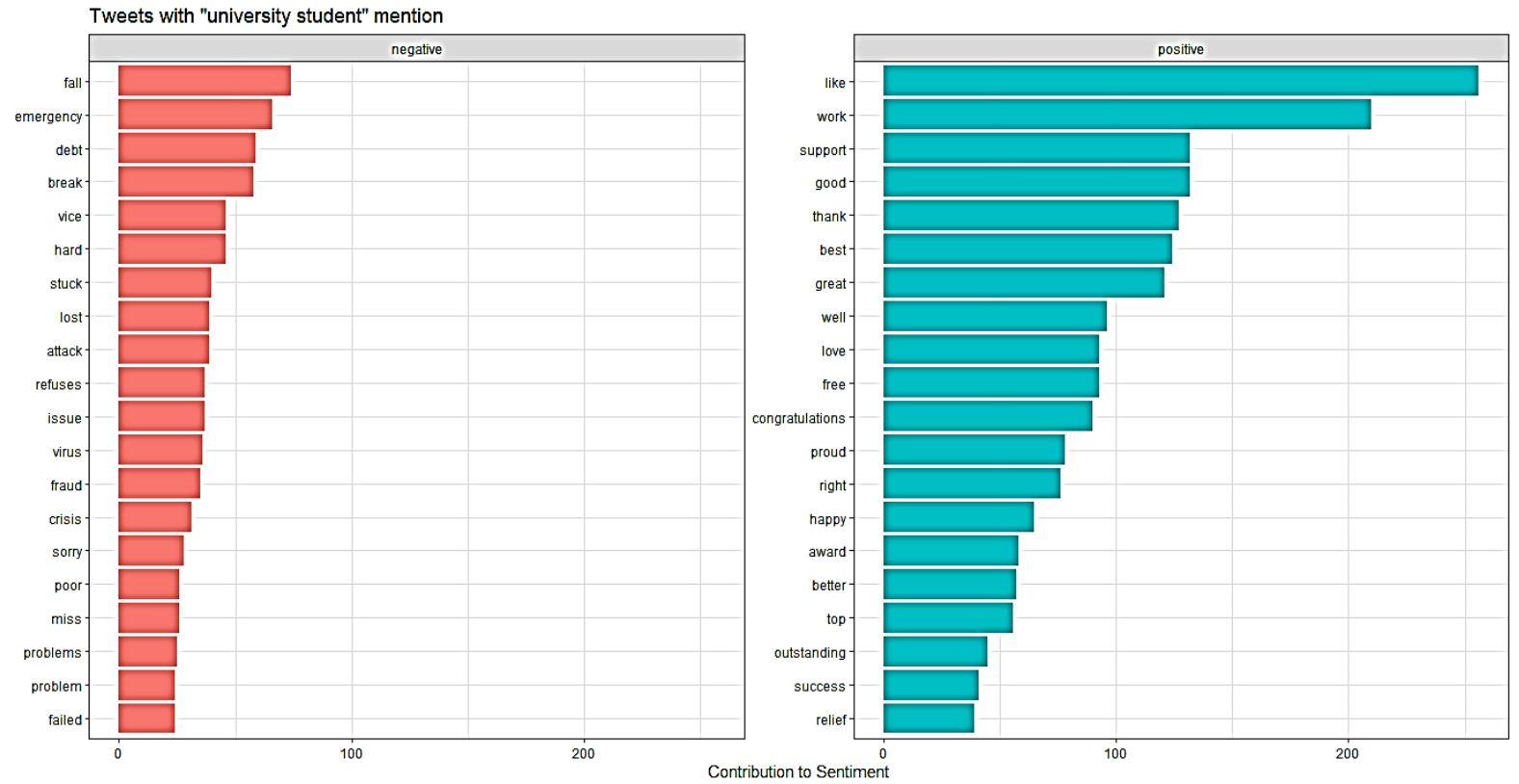

Figure 7. The most frequent words having positive and negative sentiment of the diction of tweets that include keywords of "university student".

\subsubsection{Finding Psycholingual Cues of Stress among Grouped Tweets}

To understand psycholingual cues of stress, we consider tweets written by two control groupsi.e. non-stressed students and non-stressed individuals to draw contrast among the variation of the chosen parameters against stressed and non-stressed members of the same community (student) and of universal community (general people). The target group shall be the student likely under stress and two control groups shall be students likely under no stress 
and individuals likely under no stress. In order to obtain the given specific subdivision, we aim to use the query keywords as mentioned in the Table 1 . It can be observed from the Table 1 that the connotation of query keywords with the words "virus" and "crisis" (most common negative sentiment words from previous study) for students likely in stress.

Table 1. The above table lists the query keywords that have been used for scrapping tweets of specific target groups and control groups.

\begin{tabular}{|c|c|}
\hline Target Group & Query Keywords \\
\hline Students likely in Stress & $\begin{array}{l}\text { "student crisis", "university student crisis", } \\
\text { "college student crisis", "student } \underline{\text { virus }}, \text {,", } \\
\text { "university student virus", "college student virus" }\end{array}$ \\
\hline $\begin{array}{l}\text { Non-Stressed Students (for same } \\
\text { community) }\end{array}$ & "student relax" \\
\hline $\begin{array}{l}\text { Non-Stressed Individuals (for universal } \\
\text { community) }\end{array}$ & “\#relax", "I feel relaxed" \\
\hline
\end{tabular}

A lot of research has been done on social media platforms and mental health to identify possible psycholingual detectors for stressed individuals [22]. After a comprehensive review of the existing literature, we choose psycholingual cues proposed by Lin et al. [5] in their paper for our analysis. The psycholingual cues that we aim to observe in the mentioned tweets as per Lin et al. are-

1. More usage of words from negative sentiment than positive sentiment in the content of the posted tweets/feed by stressed individuals than non-stressed individuals.

2. Lesser social interaction and engagement of tweets/feed by stressed individuals than non-stressed individuals measured in proportions of retweets, likes and comments.

3. Increased tendency towards posting during 0 to 6 in morning as a comorbidity for insomnia.

4. Higher saturation and lower brightness of the images posted by stressed individuals in contrast to that of non-stressed individuals

We shall be omitting the last psycholingual detector of stress as we don't have the permission from the respective users for the use of their posted images in research purpose. Thus, we use the TWINT tool for the scrapping tweets and corresponding metadata for the study of psycholingual detectors, and use the AFINN Lexicon for the sentiment analysis. The figure 6 depicts the sentiment distribution of the tweets using the keywords of likely stressed students. It can be observed that the majority of the total sentiment of these tweets fall in the negative category, i.e. there are more tweets of negative sentiment than of positive sentiment for each of the given keywords. This depicts that the tweets posted by students using the proposed keywords are negative in their sentiment. 


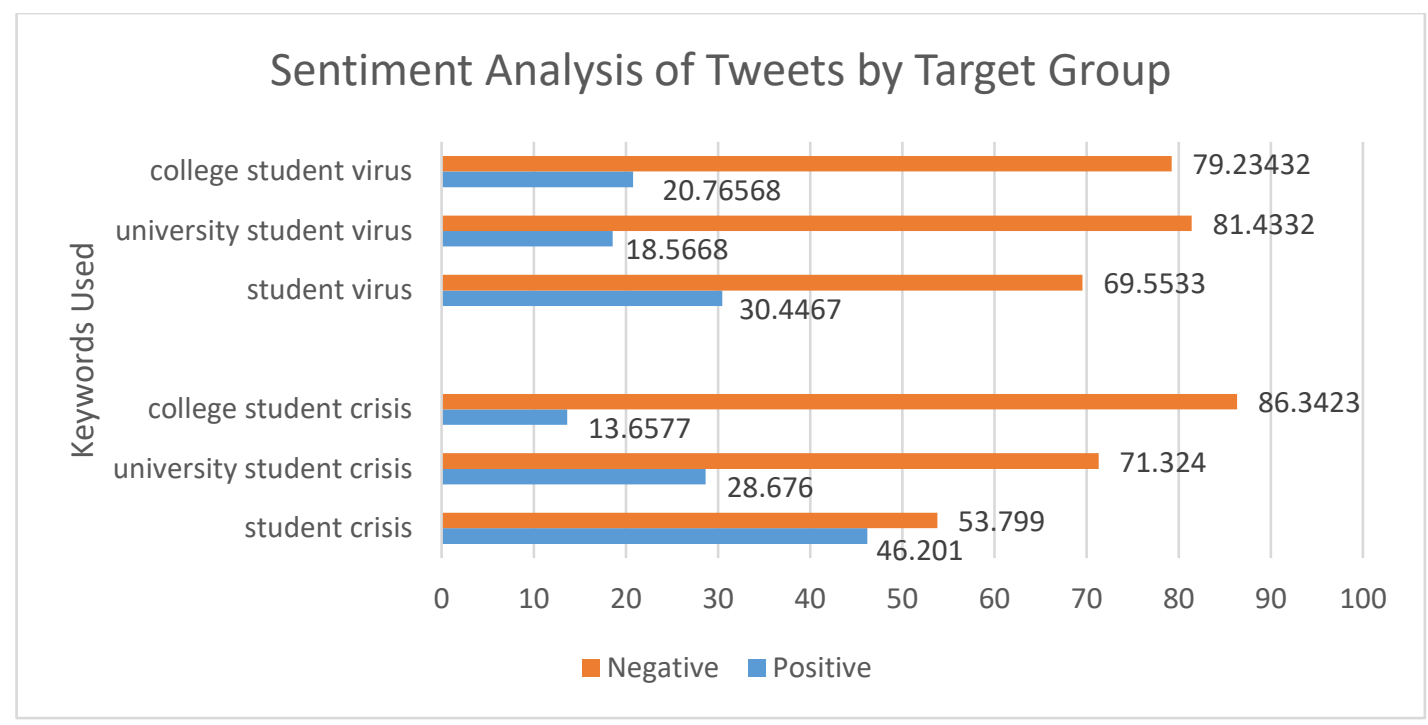

Figure 6. Sentiment distribution of the tweets using the keywords of likely stressed students

It is evident from the experiments that the presence of negative sentiment fulfils the first psycholingual detector proposed by Lin et al. in their study. It is now likely those students using the negative keywords from our initial analysis are actually engaged in writing negative sentiment content which is likely detector of possible psychological stress.

Next, we move ahead to the second psycholingual detector of lessened social engagement and increased early morning posting. Here, we contrast our results with that of the two control groups- same community and universal community. The figure 7 depicts the social engagement proportion of the Twitter Data for the students that are likely in Stress (using the "crisis" and "virus" keyword connotations), alongside the relaxed students (Same Community) and relaxed individuals (Universal Community). The same community and the universal community comprise of the control group individuals.

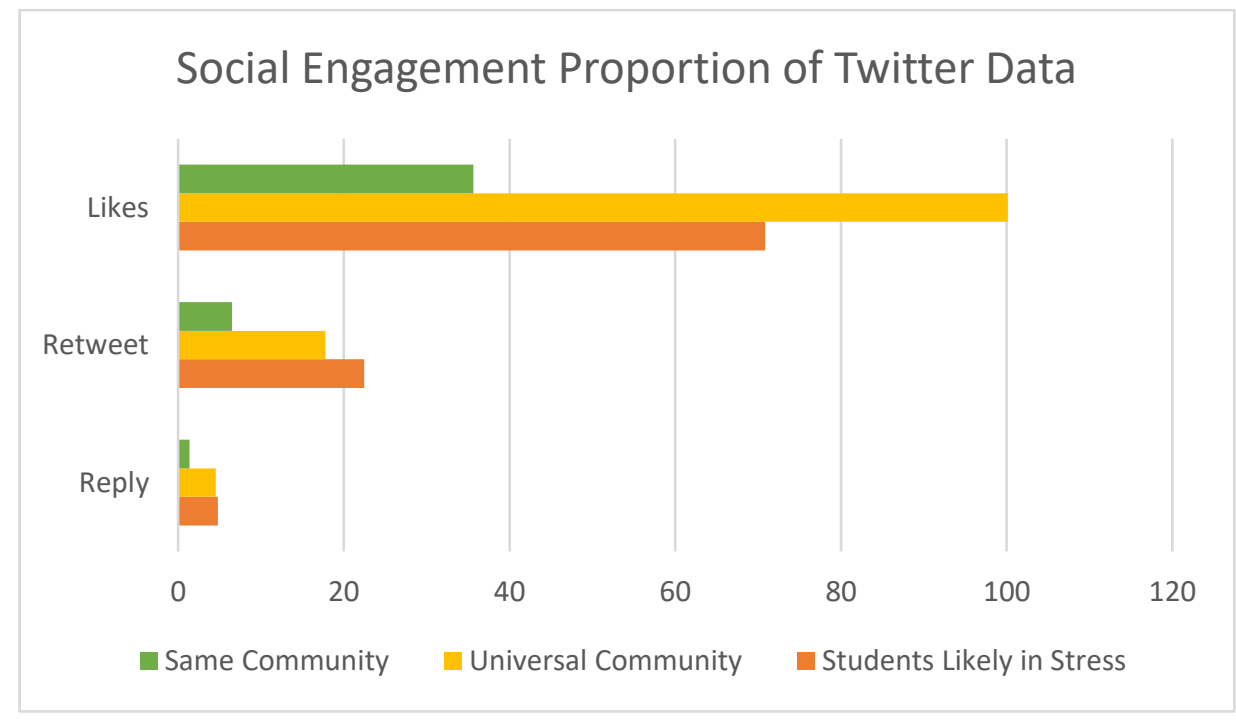

Figure 7. The social engagement proportion of the twitter data for the students among different groups 
The analysis of the social engagement proportion reveals that the students likely under stress have lesser social engagement in terms of the likes count, retweet count, and reply count in contrast to the universal community as shown in Figure 7. This proves the second psycholingual detector of stress online.

Further, we present the proportion of timestamps for each target group - Students likely in Stress, Non-Stressed Students (Same Community) and Non-Stressed Individuals (Universal Community) in Figure 8. The analysis of the timestamps from the metadata of the tweets of the target groups reveal that maximum posting of the tweets by students likely under psychological stress is done during the early morning (or late night) hours between 0 to 6 . Also, notice the minima of the tweets posted by relaxed individual of the same community and the universal community is during the same gap in which the stressed students are engaged in tweeting the post. This, despite proving the third psycholingual detector of psychological stress, also hints towards increased levels of insomnia which in turn can be a severe illness or can also act as a distinct symptom for severe mental health disorders like depression, anxiety or PTSD etc.

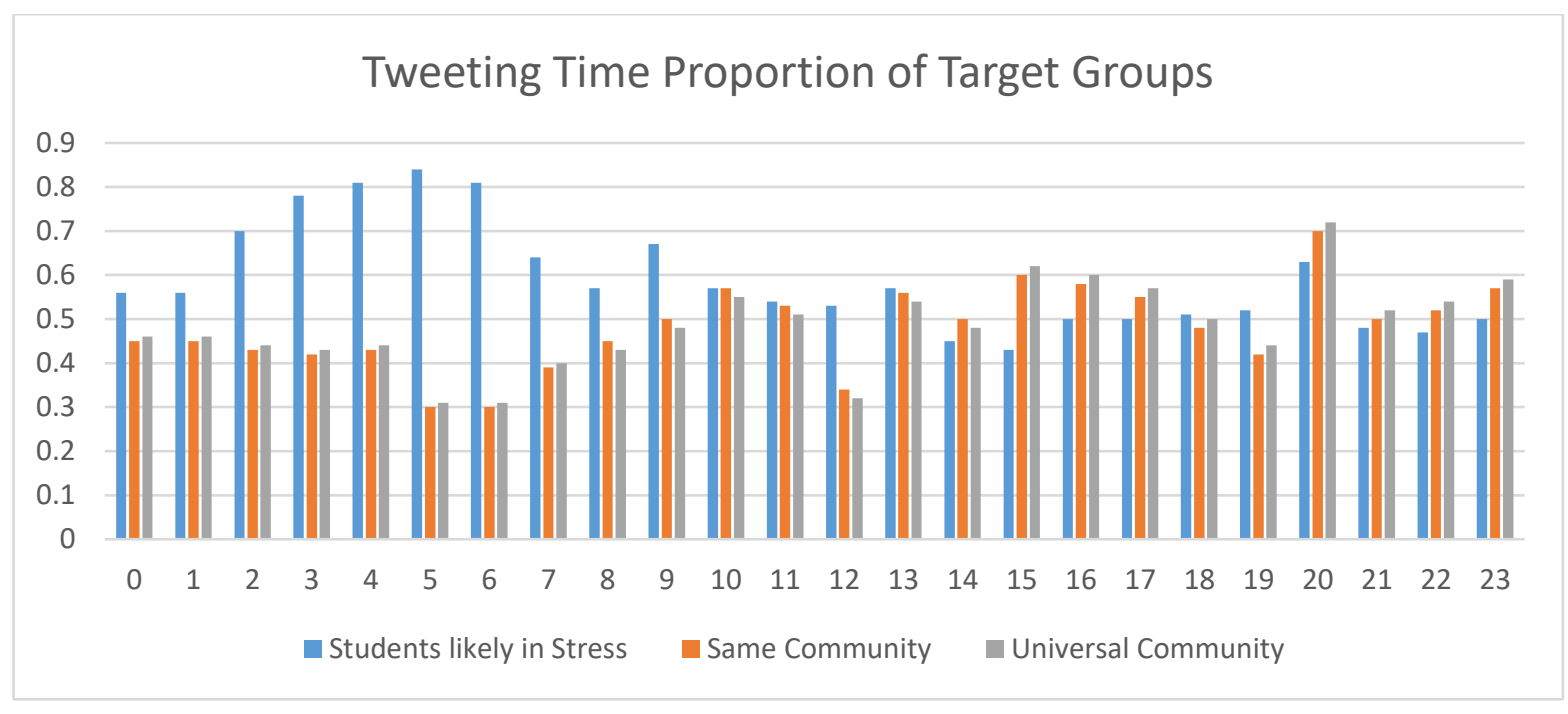

Figure 8. The proportion of timestamps for each target group of students

It is observed from the experiments that through the psycholingual detectors presented by Lin et al. in their paper, the students in the current scenario of COVID19 are most likely under psychological stress which is observed in the changing patterns of their social media activity in terms of its content and type.It is to be noted that these changes in the students are less likely to be a result of the ongoing pandemic, but rather of the non-pharmaceutical interventions like suspension of classes, rescinding of internships and job-offers and ongoing uncertainty regarding the situation in general, the education in particular. This has resulted in increased anxiety over their future career plans which in turn has resulted in unrequited psychological stress. 


\subsection{Observation from Migrant Workers' Interview}

In this section, we present the study of offline behaviour of likely stressed individuals. For the study of offline behaviour, we consider the migrant workers currently residing in the countries of Australia, India, Malaysia and Singapore. The selection of migrant workers is based on the fact that this group of individuals are the least likely to exhibit any form of online behaviour and their responses to the current stressful situations would be entirely manifested in terms of offline activities. These activities can range from simple interviews to voice their grievances to protests. With the absence of any potential online behaviour, we are certain to capture the actual true responses in wake of stressors without any cognitive bias. These countries were selected on random from the list of countries with large-scale migrant worker migration during pandemic. Also, these selected countries face the worst-impact on COVID19 on their dailywage workforce, and are being constantly covered by the international media.[7] [27-30].

Stress detection through offline behaviour provides us with a range of possible assessments. These assessments can vary from simple questionnaires/surveys to full interviews with stressed individuals [8-12]. For our study, we choose the interview path where the individuals would be asked a series of questions to complete voice their grievance with the current situation and the assessment of stress levels would be done on the basis of acoustic features of the voice. The psychoacoustic detectors of stress have been studied by Sondhi et al. (2015) [13]. The psychoacoustic detectors that we aim to identify in these interviews as per Sondhi et al. (2015) during Covid-19 pandemic are as follows.

1. Mean fundamental frequency increases under stress.

2. Spectrograms of relaxed and stressed speech are different.

The target group for our study are migrant workers from India, Singapore, Malaysia and Australia. These three states are the origin places of most of the migrant workers in the entire world. The audio samples are obtained after trimming the interviewers' voice in the interview conducted by NDTV (for India), BBC (for Malaysia and Singapore) and CNN Insider (for Australia) which are eminent news broadcasting channels constantly engaged in covering the plight of migrant workers in these tough times.[100]. The audio samples are classified into four categories as per the country of origin. As the interviews were conducted in languages of Hindi, English, Malay and Tamil the transcript were obtained and then re-narrated by 11 native speakers, 5 men and 5 women for each language in order to form the control group of the experiment. The spectrograph and the mean fundamental frequency of each of the group were obtained by the open-source PRAAT software for acoustic analysis[31-33]. We present the fundamental frequencies of the speech of Indian migrant workers and the transcript narration by non-stressed human subject in figure 9 and 10 respectively. It can be observed from figure 9 and 10 that the $F_{o}$ (fundamental frequency) of the stressed speech in higher in most of the regions as compared to that of non-stressed speech. Similar observations are seen for Singaporean, Malaysian and Australian migrant workers from figures 11, 12, 13,14, 15 and 16. 


\section{Fundamental Frequency Plot of Migrant Workers in India}

600

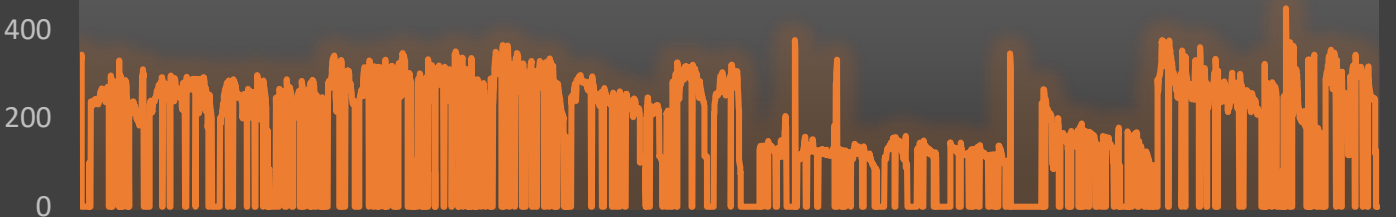

Figure 9. The fundamental frequencies plot of the interview speech samples of migrant workers staying in India

Fundamental Frequency Plot of Narration by Non-Stressed Indian Citizen

600

400

200

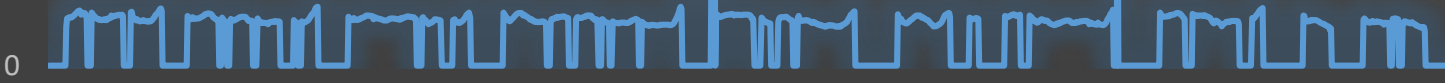

Figure 10. The fundamental frequencies plot of the transcript narration by non-stressed individuals chosen at random from the origin cities of migrant workers in India

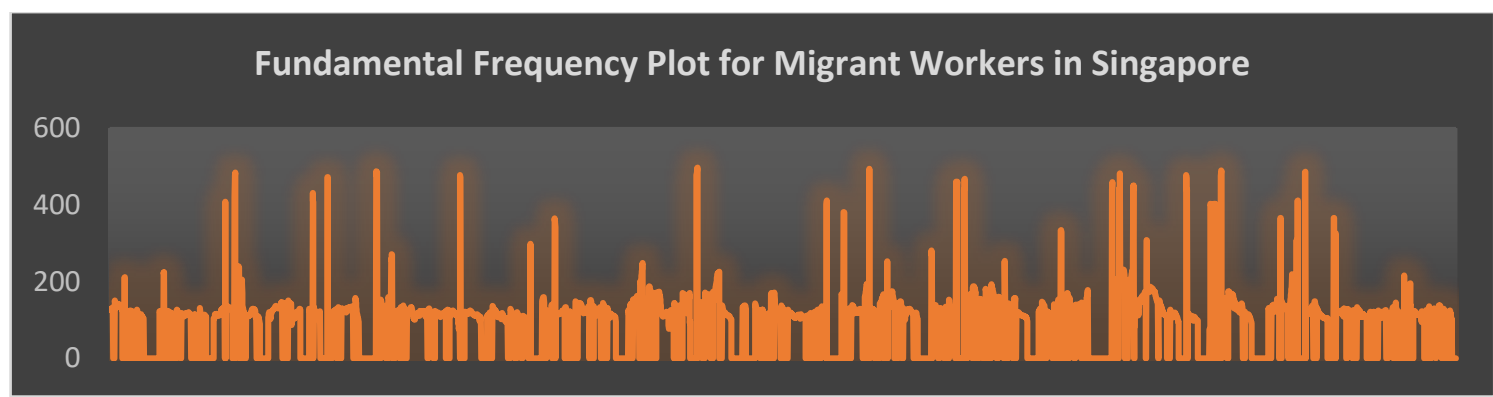

Figure 11. The fundamental frequencies plot of the interview speech samples of migrant workers staying in Singapore

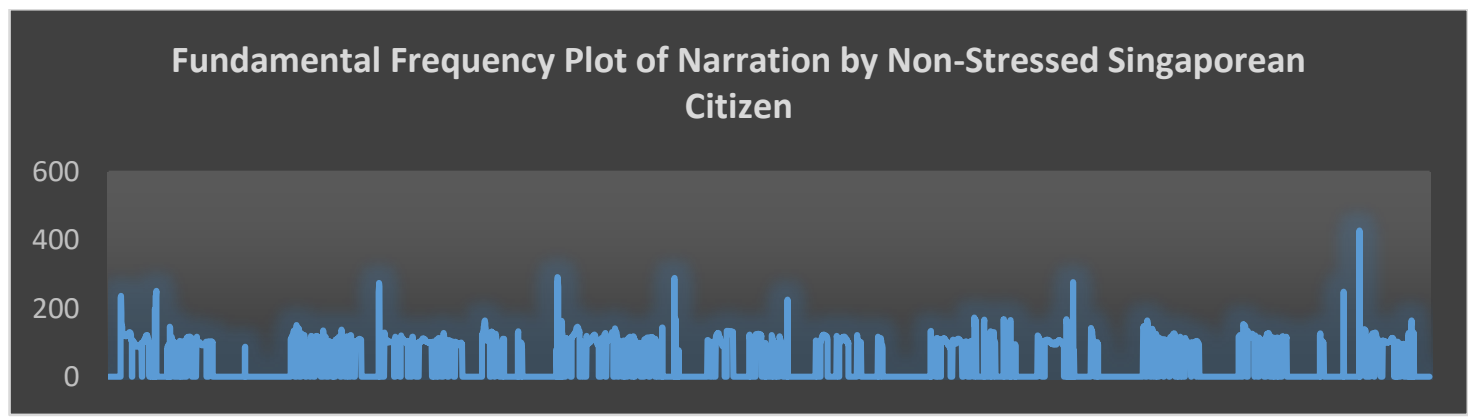

Figure 12. The fundamental frequencies plot of the transcript narration by non-stressed individuals chosen at random from the origin cities of migrant workers in Singapore 


\section{Fundamental Frequency Plot for Migrant Workers in Malaysia}

\section{0}

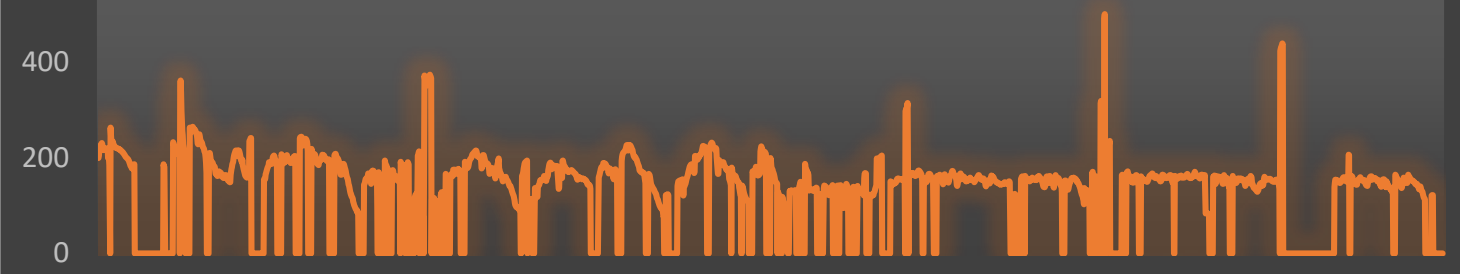

Figure 13. The fundamental frequencies plot of the interview speech samples of migrant workers staying in Malaysia

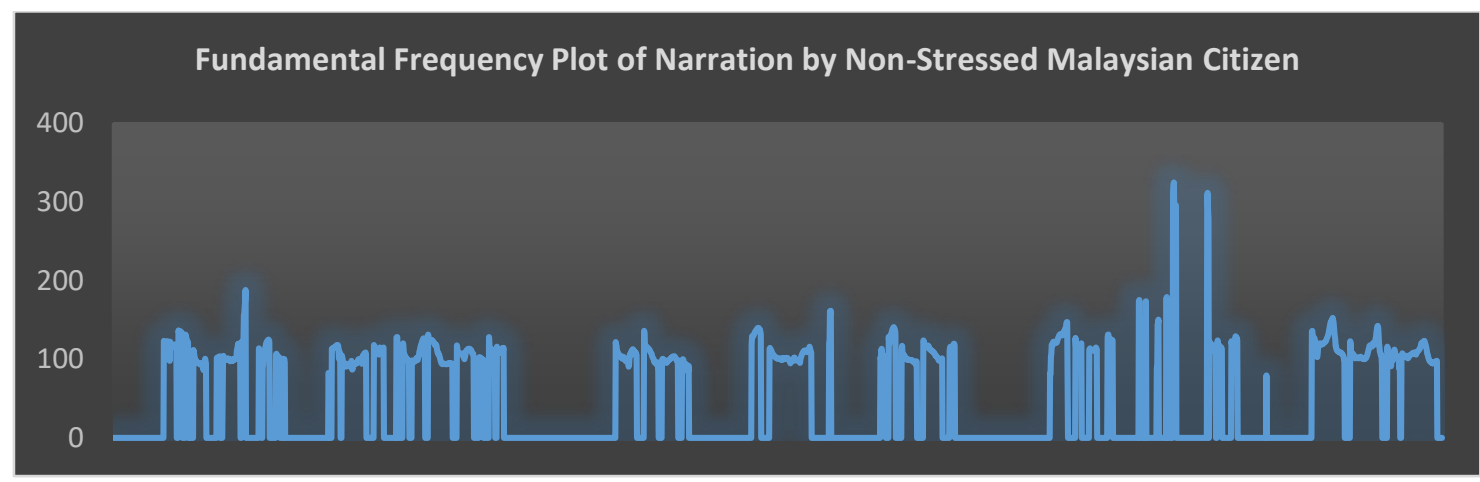

Figure 14. The fundamental frequencies plot of the transcript narration by non-stressed individuals chosen at random from the origin cities of migrant workers in Malaysia

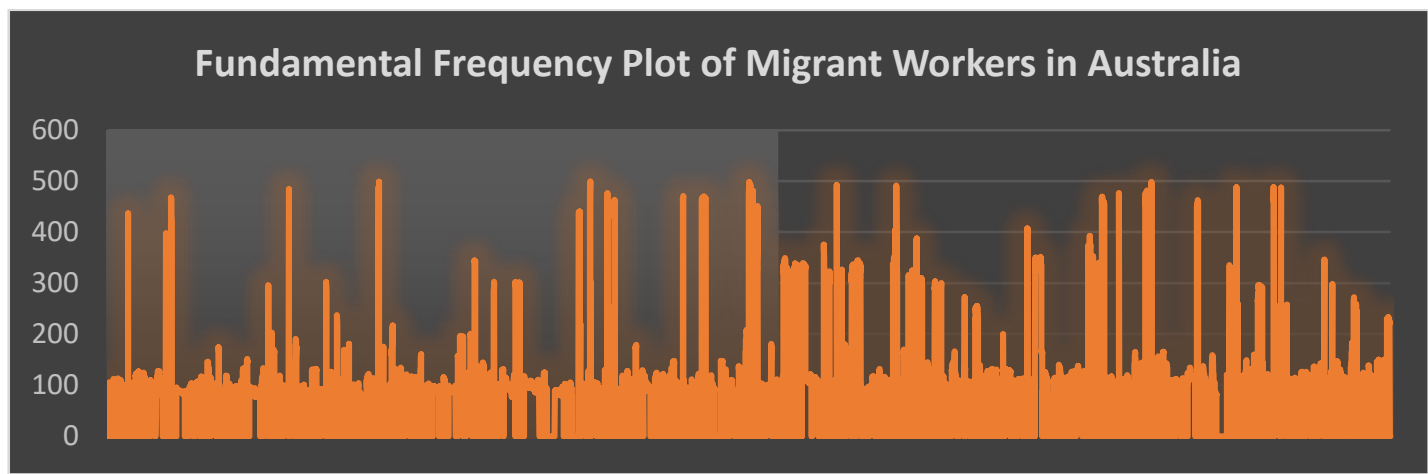

Figure 15. The fundamental frequencies plot of the interview speech samples of migrant workers staying in Australia

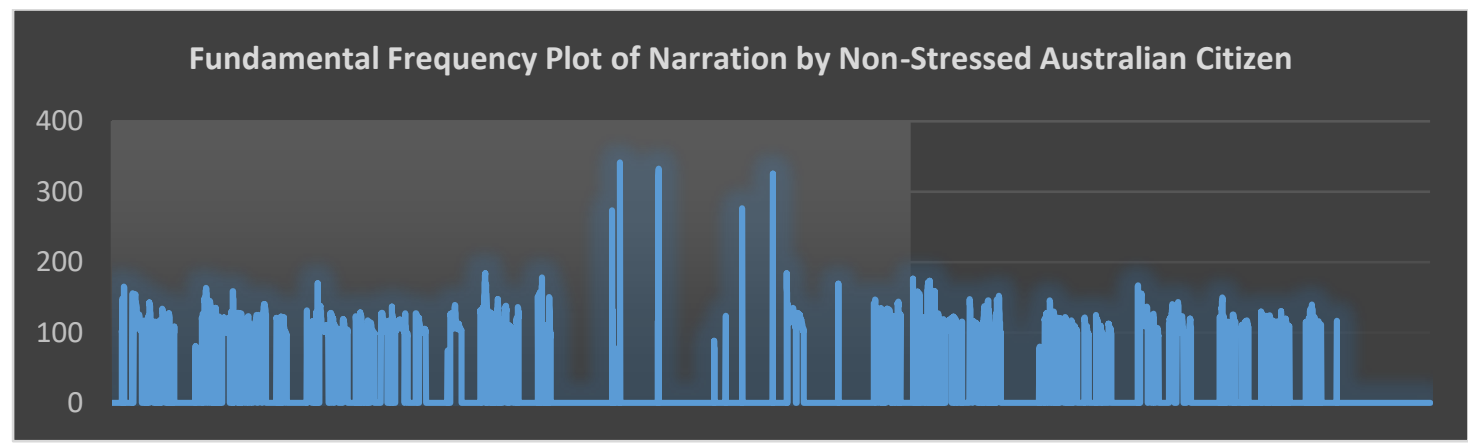

Figure 16. The fundamental frequencies plot of the transcript narration by non-stressed individuals chosen at random from the origin cities of migrant workers in Australia 
It is clear from the mean fundamental frequency plots in figures 9-16 that the migrant workers in all the major these major countries are under extreme psychological stress which is depicted in the higher values of $F_{0}$ in their speech. The contrast between the mean fundamental values of non-stressed narrations of their grievances against their own narrations depict the same. We analyse the spectrograms of their speech for a more elaborate affirmation of the hypothesis.

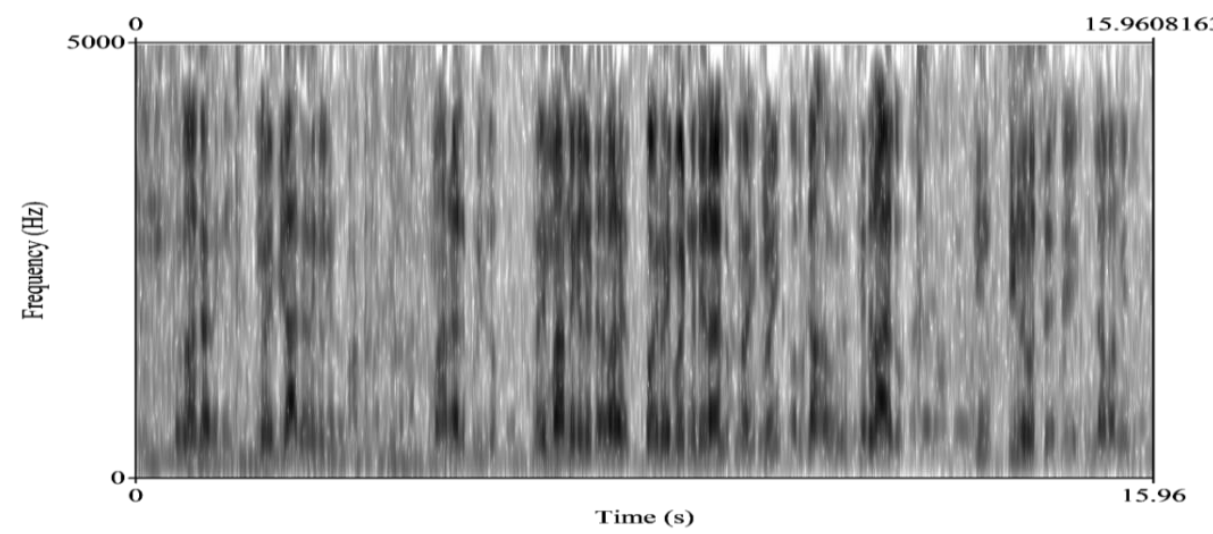

Figure 17. Spectrogram of interview samples of migrant workers staying in India (Stressed)

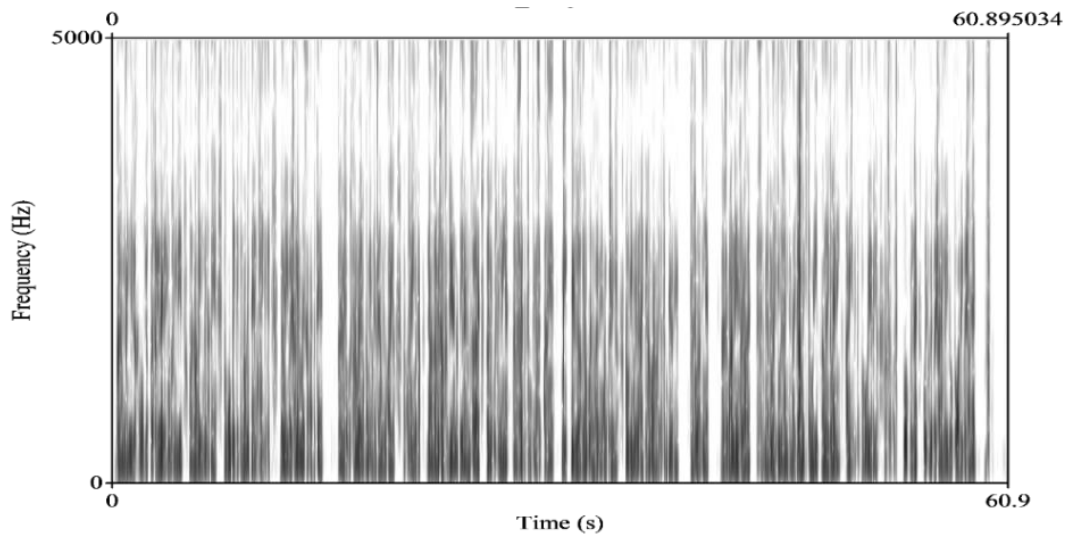

Figure 18. Spectrogram of Non-Stressed narration of Indian Migrant Workers' transcript

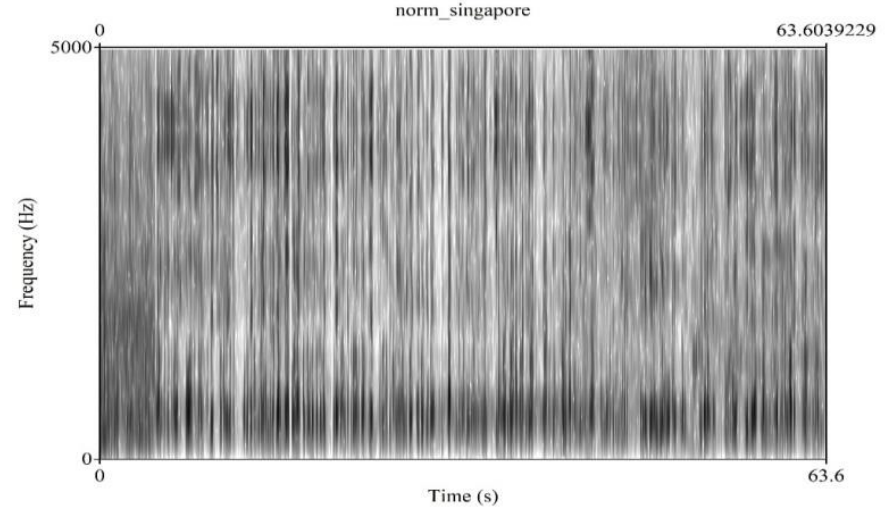

Figure 19. Spectrogram of interview samples of migrant workers staying in Singapore (stressed) 


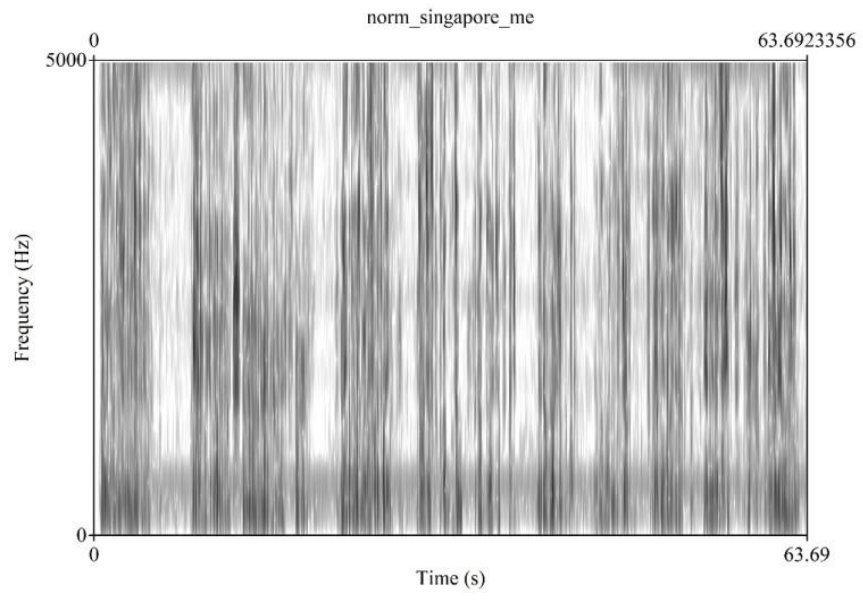

Figure 20. Spectrogram of Non-Stressed narration of Singaporean Migrant Workers' transcript

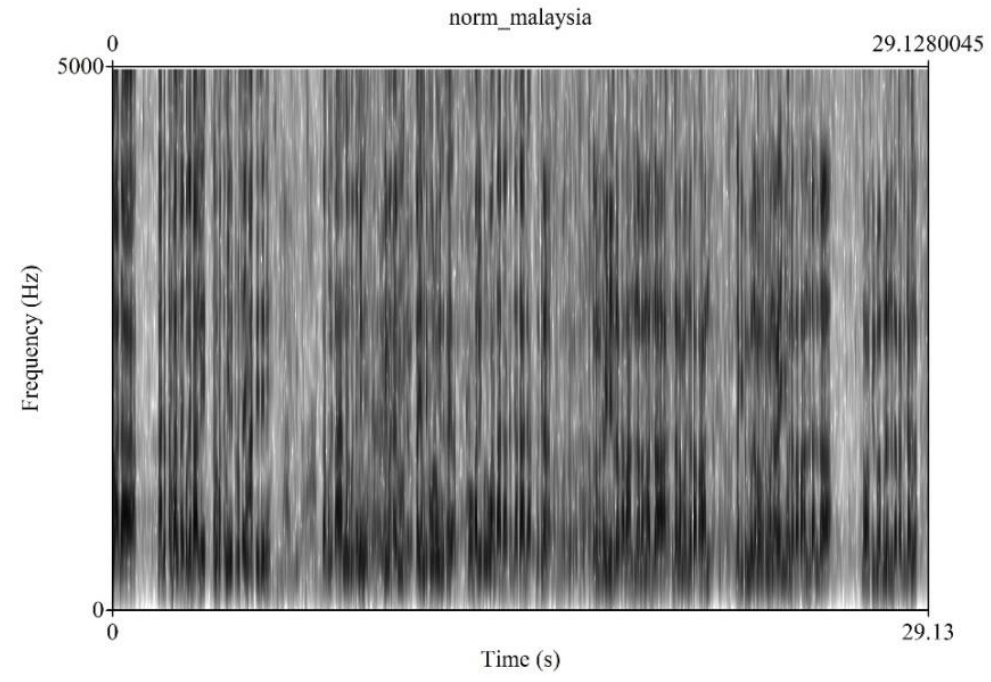

Figure 21. Spectrogram of interview samples of migrant workers staying in Malaysia (stressed)

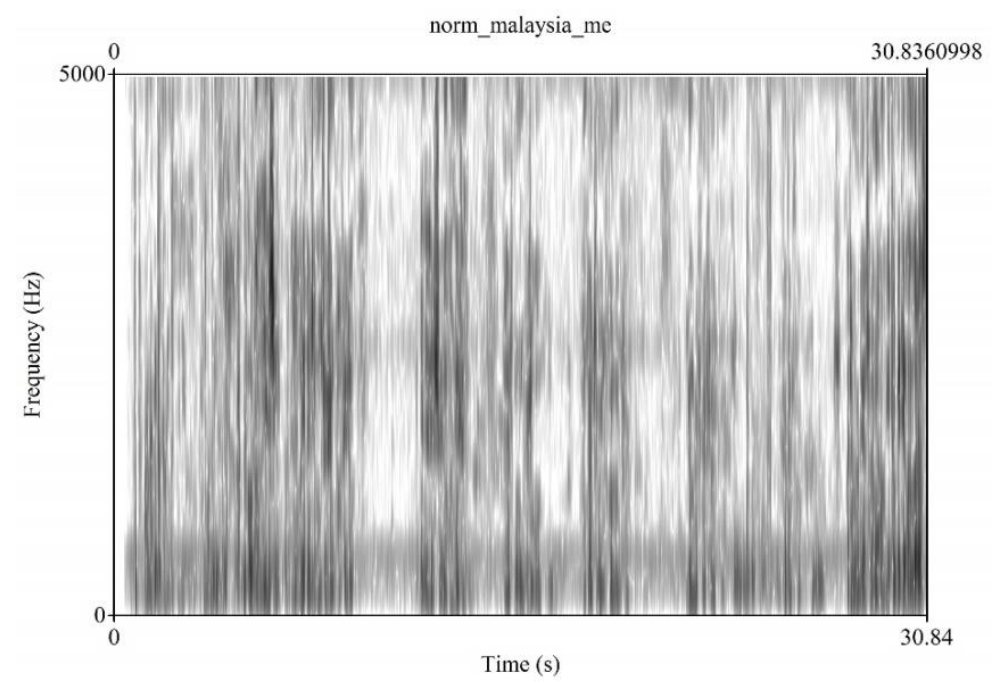

Figure 22. Spectrogram of Non-Stressed narration of Malaysia Migrant Workers' transcript 


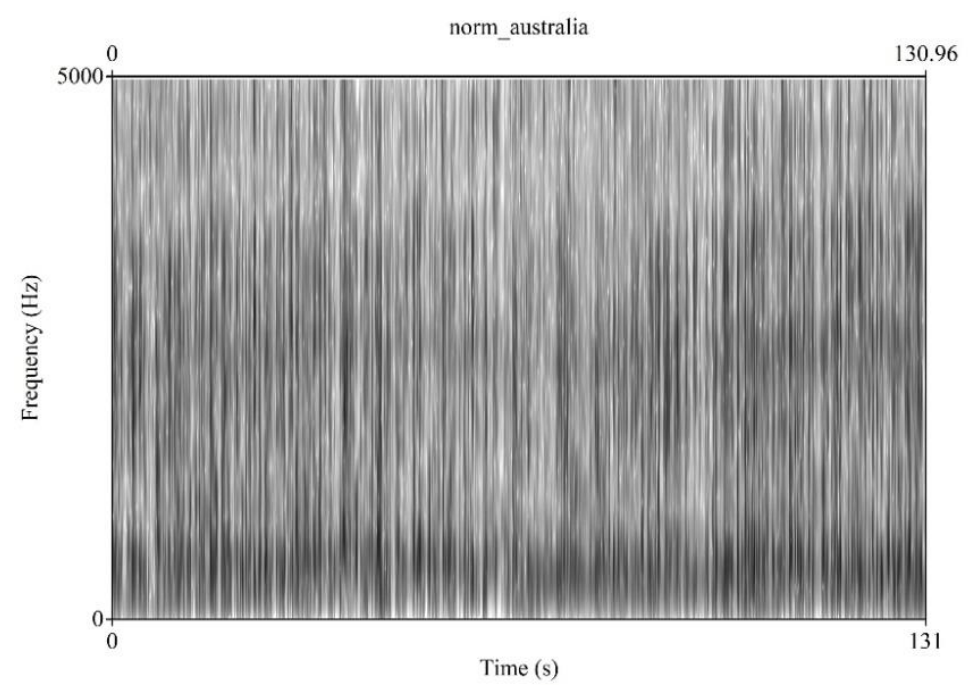

Figure 23. Spectrogram of interview samples of migrant workers staying in Australia (stressed)

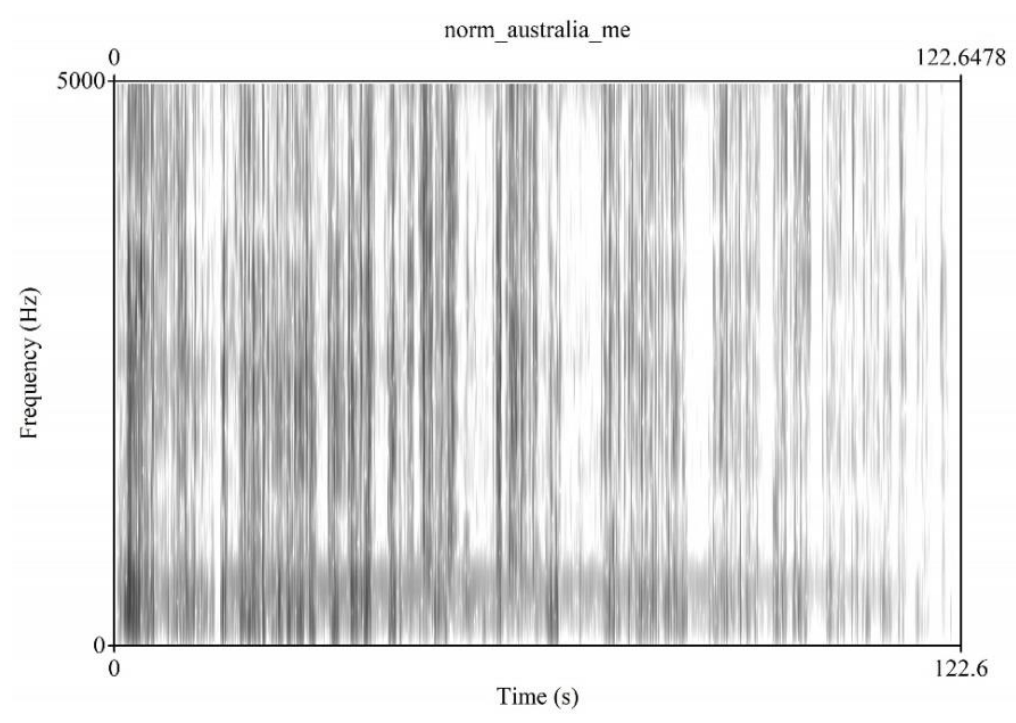

Figure 24. Spectrogram of Non-Stressed narration of Australian Migrant Workers' transcript

The figure 15-24clearly shows that on the psychoacoustic analysis of the speech by migrant workers, clear signs of psychological stress can be detected. The mean fundamental frequency of their general speech is high and the spectrograph of their speech is different in terms of density from that non-stressed narration of their speech transcripts. This proves the that the migrant workers are clearly under psychological stress due to the COVID19 and the thereby implemented non-pharmaceutical interventions.

\section{Analysis of the of the Studies Conducted}

In this section, we shall summarize our observations from the series of experiments conducted for each target group students and migrant workers. In the case of our student target group, we realized that students of the English-speaking community are under severe amount of psychological stress due to the implementation of non-pharmaceutical measures like lockdown and suspension of schools/colleges as a result of COVID19 pandemic. On a manual linguistic 
analysis of the tweets, it was found that a majority of students were concerned with problems specific to their position at the educational hierarchy. These concerns are briefly summarised in the following Table 2.

Table 2. The above table summarizes the most "frequently" mentioned concerns of students at different levels of educational hierarchy in their tweets.

\begin{tabular}{|c|c|}
\hline Position at Education System & Frequently-mentioned concerns \\
\hline School (under age of 18) & $\begin{array}{l}\text { Completion of syllabus, conduction of class- } \\
\text { test, conduction of college admission exams } \\
\text { like JEE, SAT, NEET etc. }\end{array}$ \\
\hline $\begin{array}{c}1^{\text {st }} / 2^{\text {nd }} \text { Year College/University students } \\
\text { (ages 18-21) }\end{array}$ & $\begin{array}{l}\text { Promotion to next semester/year, } \\
\text { Conduction of semester exams, Conduction } \\
\text { of lab exams, Technical flaws of online } \\
\text { classes, Evaluation of assignments }\end{array}$ \\
\hline $\begin{array}{c}3^{\text {rd }} / 4^{\text {th }} \text { Year College/University students } \\
\text { (ages 21-23) }\end{array}$ & $\begin{array}{l}\text { Rescinding of Internship offers/Job offers, } \\
\text { Promotion to next semester/year, General } \\
\text { flaws of online classes, Search for remote } \\
\text { internships, Completion of degree opted }\end{array}$ \\
\hline $\begin{array}{c}\text { Master's and PhD students (ages } 23 \text { and } \\
\text { beyond) }\end{array}$ & $\begin{array}{l}\text { Graduate Application forms, Completion of } \\
\text { dissertations/thesis/project, Completion of } \\
\text { degree awarded, Inability to reach home- } \\
\text { country, Student loans post-COVID19 }\end{array}$ \\
\hline
\end{tabular}

While the increased amounts of psychological stress triggers in the current environment of the students is reflected in their social media activity, it is also to be realized that due to the implementation of lockdown measures and suspension of classes at every academic institution, students have become more active on the social media platforms. As a result, certain social media symptoms used for detecting mental health disorders based on the volume of social media content consumed, or time spend on these platforms are likely to yield unrealistic results as the average consumption of time spent on these platforms have increased drastically. Therefore, from an academic point-of-view, it becomes essential for researchers to define a "new" normal as a baseline for defining any further psychological symptom of a mental health disorder based out of social media analytics.

In the case of our migrant worker study for acoustic detector of stress, we found that most of the migrant workers residing in the countries of India, Australia, Singapore and Malaysia are under severe psychological stress. Interviews were selected to take in the representativeness of the entire country selected. On a psychological front, it was also found that stress acts a dichotomous variable when analysed acoustically. The two variable being the comparatively higher levels of mean fundamental frequency of stressed individual's speech against nonstressed individual's speech and distinct density differences in spectrograms of stressed individual's speech and non-stressed individual's speech.

To gather greater insight from our observations on psychological stress in migrant workers, the average fundamental frequencies of the interview samples were taken and plotted against the days since the implementation of lockdown in the chosen countries. As expected, the trend of average fundamental frequency of acoustic stress follows that of days since lockdown. This depicts that most of the countries, despite their great efforts to curb and contain the spread of 
COVID19, have failed in providing any sort of psychological relief to the migrant workers who not only face the plight of COVID19, but loss of employment, lack of food, lack of shelter, and lack of hope for survival. As the data depicts, Singapore has particularly failed in doing the same, which is depicted by the break in trend. It is likely the result of the fact that migrant workers in Singapore (before May $1^{\text {st }}$ ) were kept in dormitories with abysmal living conditions. It can also be the result of late implementation of lockdown measures as depicted by the graph. Singapore, though being successful in containing the spread of COVID19, unfortunately failed in containing COVID19's psychological impact on its migrant workforce.

The figure 25 depicts the correlation between the days since lockdown implementation and psychological levels of stress depicted through acoustic stress. The data for the duration of lockdown was obtained through government websites and national newspaper.

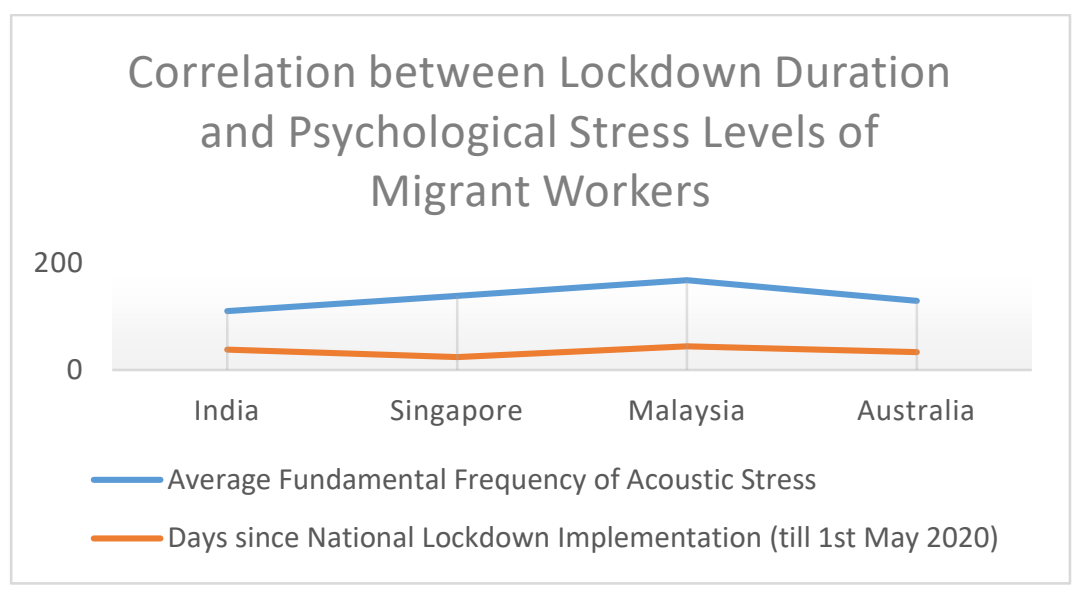

Figure 25. Correlation between the days since lockdown implementation and psychological levels of stress depicted through acoustic stress.

It is currently safe to say that government authorities of respective countries should retrospect their policies on the migrant workers and their conditions. More focus should be given on ensuring that they are provided emotional (or mental) support along with physical and financial support.

\section{Does Offline behaviour mimic Online Behaviour?}

An important question in the field of neuroscience and psychology is- Does offline behaviour mimic online behaviour. To rephrase this question, it basically involves finding behaviours of human subjects unique and distinct to only the online platforms. [1][4].

In this study, we investigated students for their online behaviour for possibility of psychological stress signals. However, it is also important to observe the presence of expletive and abusive words contributing towards the negative sentiment of their tweet diction, as shown in Figure 5-7. An important attribute with online social platforms is the lack of content moderation. There virtually exists no check over the individual's choice of words. Alongside, there exists no check for any requirement of physical contact for posting the required tweets. It means that one can post anything about anyone despite the fact that these two individuals are completely unknown to each other. With the lack of moderation of content and freedom to 
escape social connection with the receiver, the person becomes free to exploit the entire spectrum of his/ her known diction. This results in the increased frequency of words with are a taboo in terms of social norms. The presence of such words, apart from being a concern, is itself a distinctive feature of studies conducted on online platforms. It also qualifies as a measure for a successfully conducted online behaviour research.

On the neuroscience side of view, the question that the research proposes is whether more such distinct features of online behaviour can be discovered. However, there exists a wide dearth in the volume of research conducted in the field of psychological disorders on social media and their actual contribution towards the discipline. In respect to the study conducted, the table 3 lists the limitations encountered common with the field with possible approaches to overcome them, which we would focus in future.

Table 3. The shortcoming with the current research being conducted on social media platforms alongside with possible approaches to improve upon them.

\begin{tabular}{|l|l|}
\hline \multicolumn{1}{|c|}{ Limitation } \\
$\begin{array}{l}\text { Lack of tools to analyse psychological } \\
\text { stressors in local languages }\end{array}$ & $\begin{array}{l}\text { Research in the field of Sentiment Analysis } \\
\text { for non-English languages like Hindi and } \\
\text { Tamil }\end{array}$ \\
\hline $\begin{array}{l}\text { Lack of comprehensive psycholingual } \\
\text { detectors of mental health disorders for } \\
\text { social media platforms }\end{array}$ & $\begin{array}{l}\text { Offline behaviour of stressed individuals } \\
\text { can be taken as a proxy to replicate results } \\
\text { on online behaviour. }\end{array}$ \\
\hline $\begin{array}{l}\text { Lack of multi-modal approaches to } \\
\text { capture stress for online individuals } \\
\text { without use of IoT sensors }\end{array}$ & $\begin{array}{l}\text { Cross-platform tracking of social media } \\
\text { activity to obtain results from various } \\
\text { platforms. Each platforms allows for } \\
\text { different type of content input }\end{array}$ \\
\hline $\begin{array}{l}\text { Lack of ontology on detecting levels of } \\
\text { certain psychological disorders i.e. level } \\
\text { of psychological stress as per DSM-5 } \\
\text { standards cannot be predicted }\end{array}$ & $\begin{array}{l}\text { Extension of standard questionnaires like } \\
\text { DSM-5 to online applications. Testing } \\
\text { strategies for psychological disorders should } \\
\text { also involve component of online activity }\end{array}$ \\
\hline $\begin{array}{l}\text { Lack of temporal component in the } \\
\text { studies conducted to track changes in the } \\
\text { levels of psychological disorders }\end{array}$ & $\begin{array}{l}\text { Temporal activity can be tracked using } \\
\text { comprehensive time-series analysis of } \\
\text { variation of detectors of psychological } \\
\text { disorders. }\end{array}$ \\
\hline
\end{tabular}

\section{Conclusion and Future Work}

In this paper, the importance of social media is established as a tool towards understanding the psyche of individuals and its potential of contribution towards the better understanding of online-offline behaviour of human subjects. We analysed how Covid-19 pandemic impacts individuals and acts as a stressor for humans. The impact of the pandemic on students and migrant workers was studied and we arrived at the conclusion regarding their higher possibility of being in psychological stress. The neurobiology of resilience to stress was analysed. Further, the limitations faced during the conduction of the study is presented and its possible implications for the entire field. Finally, the significant open question in the field of neuroscience of human behaviour is briefed. The future work in this study would involve 
analysing further than psychological stress and building a comprehensive survey for the other comorbidities that follow stress itself like PTSD and MDD. Such studies can also be replicated for non-English based languages to capture the entire diversity of the population. A large scale analysis can be conducted to track the intensity based variations of psychological stress over a temporal axis of COVID19, or even over a geospatial and temporal axis of the dynamic spread of COVID19.

\section{References}

1. Meshi, D., Tamir, D. I., \&Heekeren, H. R. (2015). The emerging neuroscience of social media. Trends in cognitive sciences, 19(12), 771-782.

2. Franks, D. (2010). Neurosociology: The nexus between neuroscience and social psychology. Springer Science \& Business Media. Doi: 10.1007/978-1-4419-5531-9.

3. Sherman, L. E., Hernandez, L. M., Greenfield, P. M., \& Dapretto, M. (2018). What the brain 'Likes': neural correlates of providing feedback on social media. Social cognitive and affective neuroscience, 13(7), 699-707.

4. Seixas, S. A., Nield, G. E., Pynta, P., \& Silberstein, R. B. (2018). The neuroscience of social television. In Applications of Neuroscience: Breakthroughs in Research and Practice (pp. 413-426). IGI Global.

5. Lin, H., Jia, J., Guo, Q., Xue, Y., Li, Q., Huang, J., ... \& Feng, L. (2014, November). User-level psychological stress detection from social media using deep neural network. In Proceedings of the 22nd ACM international conference on Multimedia (pp. 507516).

6. Kamvar, S. D., \& Harris, J. (2011, February). We feel fine and searching the emotional web. In Proceedings of the fourth ACM international conference on Web search and data mining (pp. 117-126).

7. Lancet, T. (2020). India under COVID-19 lockdown. Lancet (London, England), 395(10233), 1315.

8. Chen, T., Yuen, P., Richardson, M., Liu, G., \& She, Z. (2014). Detection of psychological stress using a hyperspectral imaging technique. IEEE Transactions on Affective Computing, 5(4), 391-405.

9. Blevins, C. A., Weathers, F. W., Davis, M. T., Witte, T. K., \& Domino, J. L. (2015). The posttraumatic stress disorder checklist for DSM5 (PCL5): Development and initial psychometric evaluation. Journal of traumatic stress, 28(6), 489-498.

10. Nübling, M., Stößel, U., Hasselhorn, H. M., Michaelis, M., \& Hofmann, F. (2006). Measuring psychological stress and strain at work-Evaluation of the COPSOQ Questionnaire in Germany. GMS Psycho-Social Medicine, 3.

11. Guthrie, E., Black, D., Bagalkote, H., Shaw, C., Campbell, M., \& Creed, F. (1998). Psychological stress and burnout in medical students: a five-year prospective longitudinal study. Journal of the Royal Society of Medicine, 91(5), 237-243.

12. Charquero-Ballester, M., Kleim, B., Vidaurre, D., Ruff, C., Stark, E., Tuulari, J. J., \& Williams, S. C. (2020). Effective psychological treatment for PTSD changes the dynamics of specific large-scale brain networks. bioRxiv.

13. Sondhi, S., Khan, M., Vijay, R., Salhan, A. K., \&Chouhan, S. (2015). Acoustic analysis of speech under stress. IJBRA, 11(5), 417-432. 
14. van der Werff, S. J., van den Berg, S. M., Pannekoek, J. N., Elzinga, B. M., \& Van Der Wee, N. J. (2013). Neuroimaging resilience to stress: a review. Frontiers in behavioral neuroscience, $7,39$.

15. Britton, J. C., Phan, K. L., Taylor, S. F., Fig, L. M., \& Liberzon, I. (2005). Corticolimbic blood flow in posttraumatic stress disorder during script-driven imagery. Biological psychiatry, 57(8), 832-840.

16. New, A. S., Fan, J., Murrough, J. W., Liu, X., Liebman, R. E., Guise, K. G., \& Charney, D. S. (2009). A functional magnetic resonance imaging study of deliberate emotion regulation in resilience and posttraumatic stress disorder. Biological psychiatry, 66(7), 656-664.

17. Gilbertson, M. W., Shenton, M. E., Ciszewski, A., Kasai, K., Lasko, N. B., Orr, S. P., \& Pitman, R. K. (2002). Smaller hippocampal volume predicts pathologic vulnerability to psychological trauma. Nature neuroscience, 5(11), 1242-1247.

18. May, F. S., Chen, Q. C., Gilbertson, M. W., Shenton, M. E., \& Pitman, R. K. (2004). Cavum septum pellucidum in monozygotic twins discordant for combat exposure: relationship to posttraumatic stress disorder. Biological psychiatry, 55(6), 656-658.

19. Kasai, K., Yamasue, H., Gilbertson, M. W., Shenton, M. E., Rauch, S. L., \& Pitman, R. K. (2008). Evidence for acquired pregenual anterior cingulate gray matter loss from a twin study of combat-related posttraumatic stress disorder. Biological psychiatry, 63(6), 550-556.

20. Shin, L. M., Bush, G., Milad, M. R., Lasko, N. B., Brohawn, K. H., Hughes, K. C., \& Rauch, S. L. (2011). Exaggerated activation of dorsal anterior cingulate cortex during cognitive interference: a monozygotic twin study of posttraumatic stress disorder. American Journal of Psychiatry, 168(9), 979-985.

21. Sherin, J. E., \&Nemeroff, C. B. (2011). Post-traumatic stress disorder: the neurobiological impact of psychological trauma. Dialogues in clinical neuroscience, 13(3), 263.

22. Stankevich, M., Latyshev, A., Kuminskaya, E., Smirnov, I., \& Grigoriev, O. (2019, October). Depression Detection from Social Media Texts. In Data Analytics and Management in Data Intensive Domains: XXI International Conference $D A M D I D / R C D L ' 2019,2019 .-496$ p. (p. 352).

23. Newcomb, M. D., Huba, G. J., \&Bentler, P. M. (1981). A multidimensional assessment of stressful life events among adolescents: Derivation and correlates. Journal of health and social behavior, 400-415.

24. Newcomb, M. D., Huba, G. J., \& Bentler, P. M. (1986). Life change events among adolescents: An empirical consideration of some methodological issues. Journal of Nervous and Mental Disease.

25. Duan, L., \& Zhu, G. (2020). Psychological interventions for people affected by the COVID-19 epidemic. The Lancet Psychiatry, 7(4), 300-302.

26. Dalton, L., Rapa, E., \& Stein, A. (2020). Protecting the psychological health of children through effective communication about COVID-19. The Lancet Child \& Adolescent Health, 4(5), 346-347.

27. Davey, S., Davey, A., \& Jain, R. (2020). Impact of Social Distancing on Curtailing COVID 2019 Epidemic in India: A Systematic Review by SWOT Analysis Approach. Epidemiology International (E-ISSN: 2455-7048), 5(1), 44-49.

28. Chaturvedi, P., \&Ramalingam, N. (2020). Into the past in the times of COVID pandemic. Cancer Research, Statistics, and Treatment, 3(5), 94.

29. Al Dahdah, M., Ferry, M., Guérin, I., \&Venkatasubramanian, G. (2020). The Covid-19 Crisis in India. 
30. Bhagat, R. B., Reshmi, R. S., Sahoo, H., Roy, A. K., \& Govil, D. (2020). The COVID19, Migration and Livelihood in India (No. id: 13054).

31. Styler, W. (2013). Using Praat for linguistic research. University of Colorado at Boulder Phonetics Lab.

32. Owren, M. J. (2008). GSU Praat Tools: Scripts for modifying and analyzing sounds using Praat acoustics software. Behavior research methods, 40(3), 822-829.

33. Amir, O., Wolf, M., \& Amir, N. (2009). A clinical comparison between two acoustic analysis softwares: MDVP and Praat. Biomedical Signal Processing and Control, 4(3), 202-205.

34. Bonne, O., Brandes, D., Gilboa, A., Gomori, J. M., Shenton, M. E., Pitman, R. K., $\&$ Shalev, A. Y. (2001). Longitudinal MRI study of hippocampal volume in trauma survivors with PTSD. American Journal of Psychiatry, 158(8), 1248-1251.

35. Woon, F. L., \& Hedges, D. W. (2008). Hippocampal and amygdala volumes in children and adults with childhood maltreatment related posttraumatic stress disorder: A meta analysis. Hippocampus, 18(8), 729-736.

36. Kitayama, N., Vaccarino, V., Kutner, M., Weiss, P., \& Bremner, J. D. (2005). Magnetic resonance imaging (MRI) measurement of hippocampal volume in posttraumatic stress disorder: a meta-analysis. Journal of affective disorders, 88(1), 79-86.

37. Jatzko, A., Rothenhöfer, S., Schmitt, A., Gaser, C., Demirakca, T., Weber-Fahr, W., ... \&Braus, D. F. (2006). Hippocampal volume in chronic posttraumatic stress disorder (PTSD): MRI study using two different evaluation methods. Journal of Affective Disorders, 94(1-3), 121-126.

38. Armony, J. L., Corbo, V., Clément, M. H., \& Brunet, A. (2005). Amygdala response in patients with acute PTSD to masked and unmasked emotional facial expressions. American Journal of Psychiatry, 162(10), 1961-1963.

39. El Khoury-Malhame, M., Reynaud, E., Soriano, A., Michael, K., Salgado-Pineda, P., Zendjidjian, X., \& Samuelian, J. C. (2011). Amygdala activity correlates with attentional bias in PTSD. Neuropsychologia, 49(7), 1969-1973.

40. Andero, R., Brothers, S. P., Jovanovic, T., Chen, Y. T., Salah-Uddin, H., Cameron, M., \& Binder, E. B. (2013). Amygdala-dependent fear is regulated by Oprl1 in mice and humans with PTSD. Science translational medicine, 5(188), 188ra73-188ra73.

41. Avecillas-Chasin, J. M., Justo, M., Levinson, S., Koek, R., Krahl, S. E., Chen, J. W., \& Bari, A. (2020). Structural correlates of emotional response to electrical stimulation of the amygdala in subjects with PTSD. Brain Stimulation: Basic, Translational, and Clinical Research in Neuromodulation, 13(2), 424-426.

42. Morey, R. A., Clarke, E. K., Haswell, C. C., Phillips, R. D., Clausen, A. N., Mufford, M. S., ... \&Dedert, E. (2020). Amygdala nuclei volume and shape in military veterans with posttraumatic stress disorder. Biological Psychiatry: Cognitive Neuroscience and Neuroimaging, 5(3), 281-290.

43. Woodward, S. H., Kaloupek, D. G., Streeter, C. C., Martinez, C., Schaer, M., \&Eliez, S. (2006). Decreased anterior cingulate volume in combat-related PTSD. Biological psychiatry, 59(7), 582-587.

44. Hamner, M. B., Lorberbaum, J. P., \& George, M. S. (1999). Potential role of the anterior cingulate cortex in PTSD: review and hypothesis. Depression and anxiety, 9(1), 1-14.

45. Thomaes, K., Dorrepaal, E., Draijer, N., de Ruiter, M. B., van Balkom, A. J., Smit, J. H., \&Veltman, D. J. (2010). Reduced anterior cingulate and orbitofrontal volumes in child abuse-related complex PTSD. The Journal of clinical psychiatry, 71(12), 16361644.

46. Thomaes, K., Dorrepaal, E., Draijer, N., de Ruiter, M. B., Elzinga, B. M., Sjoerds, Z., ... \&Veltman, D. J. (2013). Increased anterior cingulate cortex and hippocampus 
activation in Complex PTSD during encoding of negative words. Social cognitive and affective neuroscience, 8(2), 190-200.

47. Kitayama, N., Quinn, S., \&Bremner, J. D. (2006). Smaller volume of anterior cingulate cortex in abuse-related posttraumatic stress disorder. Journal of affective disorders, 90(2-3), 171-174.

48. Gosnell, S. N., Oh, H., Schmidt, J., Oldham, J., Fowler, J. C., Patriquin, M., \& Salas, R. (2020). Right temporal pole volume reduction in PTSD. Progress in NeuroPsychopharmacology and Biological Psychiatry, 100, 109890.

49. Kampa, M., Schick, A., Sebastian, A., Wessa, M., Tüscher, O., Kalisch, R., \& Yuen, K. (2020). Replication of fMRI group activations in the neuroimaging battery for the Mainz Resilience Project (MARP). NeuroImage, 204, 116223.

50. Henze, G. I., Konzok, J., Kreuzpointner, L., Bärtl, C., Peter, H., Giglberger, M., \&Wüst, S. (2020). Increasing deactivation of limbic structures over psychosocial stress exposure time. Biological Psychiatry: Cognitive Neuroscience and Neuroimaging.

51. Seligowski, A. V., Hill, S. B., King, C. D., Wingo, A. P., \&Ressler, K. J. (2020). Understanding resilience: biological approaches in at-risk populations. In Stress Resilience (pp. 133-148). Academic Press.

52. Ganzel, B. L., Kim, P., Glover, G. H., \& Temple, E. (2008). Resilience after 9/11: multimodal neuroimaging evidence for stress-related change in the healthy adult brain. Neuroimage, 40(2), 788-795.

53. van der Werff, S. J., Pannekoek, J. N., Stein, D. J., \& van der Wee, N. J. (2013). Neuroimaging of resilience to stress: current state of affairs. Human Psychopharmacology: Clinical and Experimental, 28(5), 529-532.

54. Bolsinger, J., Seifritz, E., Kleim, B., \&Manoliu, A. (2018). Neuroimaging correlates of resilience to traumatic events - a comprehensive review. Frontiers in psychiatry, 9, 693.

55. Carnevali, L., Koenig, J., Sgoifo, A., \& Ottaviani, C. (2018). Autonomic and brain morphological predictors of stress resilience. Frontiers in neuroscience, 12, 228.

56. Quaedflieg, C. W., Meyer, T., \&Smeets, T. (2013). The imaging Maastricht Acute Stress Test (iMAST): a neuroimaging compatible psychophysiological stressor. Psychophysiology, 50(8), 758-766.

57. Das, N. (2020). Psychiatrist in post-COVID-19 era-Are we prepared?.Asian Journal of Psychiatry, 51, 102082-102082.

58. Krystal, J. H., \& McNeil, R. L. (2020). Responding to the hidden pandemic for healthcare workers: stress. Nature Medicine, 1-1.

59. Taylor, S., Landry, C., Paluszek, M., Fergus, T. A., McKay, D., \&Asmundson, G. J. (2020). Development and Initial Validation of the COVID Stress Scales. Journal of Anxiety Disorders, 102232.

60. Shevlin, M., McBride, O., Murphy, J., Miller, J. G., Hartman, T. K., Levita, L., \& Bennett, K. M. (2020). Anxiety, Depression, Traumatic Stress, and COVID-19 Related Anxiety in the UK General Population During the COVID-19 Pandemic. Preprint. 10.31234/osf.io/hb6nq.

61. Dutheil, F., Mondillon, L., \& Navel, V. (2020). PTSD as the second tsunami of the SARS-Cov2 pandemic. Psychological Medicine, 1-6.

62. Onyeaka, H. K., Zahid, S., \& Patel, R. S. (2020). The unaddressed behavioral health aspect during the coronavirus pandemic. Cureus, 12(3).

63. Sood, S. (2020). Psychological effects of the Coronavirus disease-2019 pandemic. Research \& Humanities in Medical Education, 7, 23-26. 
64. Luginaah, I., Elkins, D., Maticka-Tyndale, E., Landry, T., \&Mathui, M. (2005). Challenges of a pandemic: HIV/AIDS-related problems affecting Kenyan widows. Social Science \& Medicine, 60(6), 1219-1228.

65. Matsuishi, K., Kawazoe, A., Imai, H., Ito, A., Mouri, K., Kitamura, N., \& Hitokoto, H. (2012). Psychological impact of the pandemic (H1N1) 2009 on general hospital workers in Kobe. Psychiatry and clinical neurosciences, 66(4), 353-360.

66. Lehmann, M., Bruenahl, C. A., Löwe, B., Addo, M. M., Schmiedel, S., Lohse, A. W., \& Schramm, C. (2015). Ebola and psychological stress of health care professionals. Emerging infectious diseases, 21(5), 913.

67. Hugo, M., Declerck, H., Fitzpatrick, G., Severy, N., Gbabai, O. B. M., \& Decroo, T. (2015). Post-traumatic stress reactions in Ebola virus disease survivors in Sierra Leone. Emerg Med (Los Angel), 5(6), 1-4.

68. Trichopoulos, D., Zavitsanos, X., Katsouyanni, K., Tzonou, A., \&Dalla-Vorgia, P. (1983). Psychological stress and fatal heart attack: the Athens (1981) earthquake natural experiment. The Lancet, 321(8322), 441-444.

69. MacGeorge, E. L., Samter, W., Feng, B., Gillihan, S. J., \& Graves, A. R. (2007). After 9/11: Goal disruption, emotional support, and psychological health in a lower exposure sample. Health Communication, 21(1), 11-22.

70. DiGrande, L., Perrin, M. A., Thorpe, L. E., Thalji, L., Murphy, J., Wu, D., \& Brackbill, R. M. (2008). Posttraumatic stress symptoms, PTSD, and risk factors among lower Manhattan residents 2-3 years after the September 11, 2001 terrorist attacks. Journal of Traumatic Stress: Official Publication of The International Society for Traumatic Stress Studies, 21(3), 264-273.

71. Schurz, M., Radua, J., Aichhorn, M., Richlan, F., \&Perner, J. (2014). Fractionating theory of mind: a meta-analysis of functional brain imaging studies. Neuroscience \& Bio behavioral Reviews, 42, 9-34.

72. Saxe, R., \& Kanwisher, N. (2003). People thinking about thinking people: the role of the temporo-parietal junction in "theory of mind". Neuroimage, 19(4), 1835-1842.

73. Wolf, I., Dziobek, I., \&Heekeren, H. R. (2010). Neural correlates of social cognition in naturalistic settings: a model-free analysis approach. Neuroimage, 49(1), 894-904.

74. Falk, E., O'Donnell, M. B., \& Lieberman, M. D. (2012). Getting the word out: neural correlates of enthusiastic message propagation. Frontiers in Human Neuroscience, 6, 313.

75. Falk, E. B., Morelli, S. A., Welborn, B. L., Dambacher, K., \& Lieberman, M. D. (2013). Creating buzz: the neural correlates of effective message propagation. Psychological Science, 24(7), 1234-1242.

76. Cascio, C. N., O'Donnell, M. B., Bayer, J., Tinney Jr, F. J., \& Falk, E. B. (2015). Neural correlates of susceptibility to group opinions in online word-of-mouth recommendations. Journal of Marketing Research, 52(4), 559-575.

77. Naaman, M., Boase, J., \& Lai, C. H. (2010, February). Is it really about me? Message content in social awareness streams. In Proceedings of the 2010 ACM conference on Computer supported cooperative work (pp. 189-192).

78. Northoff, G., Heinzel, A., De Greck, M., Bermpohl, F., Dobrowolny, H., \&Panksepp, J. (2006). Self-referential processing in our brain - a meta-analysis of imaging studies on the self. Neuroimage, 31(1), 440-457.

79. Tamir, D. I., \& Mitchell, J. P. (2012). Disclosing information about the self is intrinsically rewarding. Proceedings of the National Academy of Sciences, 109(21), 8038-8043.

80. Fareri, D. S., \& Delgado, M. R. (2014). Social rewards and social networks in the human brain. The Neuroscientist, 20(4), 387-402. 
81. Ruff, C. C., \& Fehr, E. (2014). The neurobiology of rewards and values in social decision making. Nature Reviews Neuroscience, 15(8), 549-562.

82. Morelli, S. A., Torre, J. B., \&Eisenberger, N. I. (2014). The neural bases of feeling understood and not understood. Social Cognitive and Affective Neuroscience, 9(12), 1890-1896.

83. Klucharev, V., Hytönen, K., Rijpkema, M., Smidts, A., \&Fernández, G. (2009). Reinforcement learning signal predicts social conformity. Neuron, 61(1), 140-151.

84. Campbell-Meiklejohn, D. K., Bach, D. R., Roepstorff, A., Dolan, R. J., \& Frith, C. D. (2010). How the opinion of others affects our valuation of objects. Current Biology, 20(13), 1165-1170.

85. Meshi, D., Biele, G., Korn, C. W., \&Heekeren, H. R. (2012). How expert advice influences decision making. PLoS One, 7(11).

86. Davey, C. G., Allen, N. B., Harrison, B. J., Dwyer, D. B., \&Yücel, M. (2010). Being liked activates primary reward and midline self-related brain regions. Human brain mapping, 31(4), 660-668.

87. Izuma, K., Saito, D. N., \&Sadato, N. (2008). Processing of social and monetary rewards in the human striatum. Neuron, 58(2), 284-294.

88. Korn, C. W., Prehn, K., Park, S. Q., Walter, H., \&Heekeren, H. R. (2012). Positively biased processing of self-relevant social feedback. Journal of Neuroscience, 32(47), 16832-16844.

89. Harbaugh, W. T., Mayr, U., \&Burghart, D. R. (2007). Neural responses to taxation and voluntary giving reveal motives for charitable donations. Science, 316(5831), 16221625.

90. Haruno, M., Kimura, M., \& Frith, C. D. (2014). Activity in the nucleus accumbens and amygdala underlies individual differences in prosocial and individualistic economic choices. Journal of Cognitive Neuroscience, 26(8), 1861-1870.

91. Arnone, M. P., Small, R. V., Chauncey, S. A., \& McKenna, H. P. (2011). Curiosity, interest and engagement in technology-pervasive learning environments: a new research agenda. Educational Technology Research and Development, 59(2), 181-198.

92. Gruber, M. J., Gelman, B. D., \&Ranganath, C. (2014). States of curiosity modulate hippocampus-dependent learning via the dopaminergic circuit. Neuron, 84(2), 486-496.

93. Fliessbach, K., Weber, B., Trautner, P., Dohmen, T., Sunde, U., Elger, C. E., \& Falk, A. (2007). Social comparison affects reward-related brain activity in the human ventral striatum. science, 318(5854), 1305-1308.

94. Morelli, S. A., Sacchet, M. D., \&Zaki, J. (2015). Common and distinct neural correlates of personal and vicarious reward: A quantitative meta-analysis. NeuroImage, 112, 244253.

95. Ptak, R. (2012). The frontoparietal attention network of the human brain: action, saliency, and a priority map of the environment. The Neuroscientist, 18(5), 502-515.

96. Alvarez, J. A., \& Emory, E. (2006). Executive function and the frontal lobes: a metaanalytic review. Neuropsychology review, 16(1), 17-42.

97. Rizzolatti, G., \&Luppino, G. (2001). The cortical motor system. Neuron, 31(6), 889901.

98. OSINT Team. (2018). Twint Project TWINT -Twitter Intelligence Tool. Github. Retrieved 3 May 2020 via https://github.com/twintproject/twint.

99. Silge J, Robinson D (2016). "Tidytext: Text Mining and Analysis Using Tidy Data Principles in R".

100. NDTV Interview Data https://www.youtube.com/playlist?list=PLpSH-HCe7ZpZ81fUY2wg4BK7JWgmApeq\&advanced_settings=1\&disable_polymer=1 